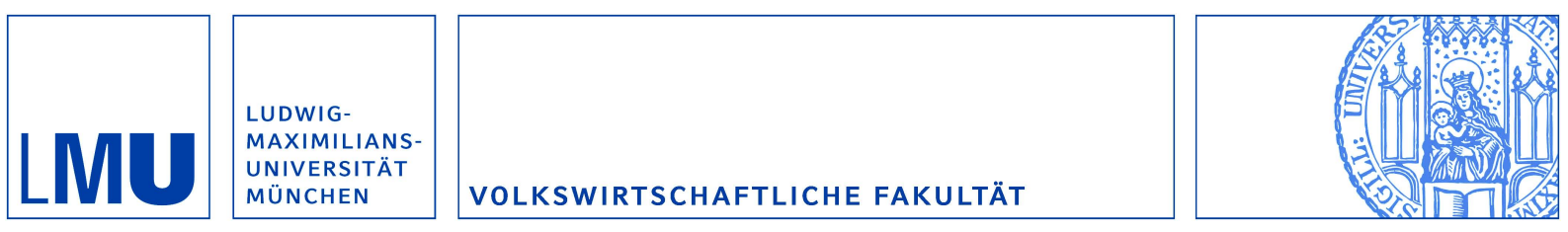

Seitz, Michael; Tarasov, Alexander und Zakharenko, Roman: Trade Costs, Conflicts, and Defense Spending

Munich Discussion Paper No. 2013-11

Department of Economics

University of Munich

Volkswirtschaftliche Fakultät

Ludwig-Maximilians-Universität München

Online at https://doi.org/10.5282/ubm/epub. 15733 


\title{
Trade Costs, Conflicts, and Defense Spending*
}

\author{
Michael Seitz \\ Boston Consulting Group
}

\author{
Alexander Tarasov \\ University of Munich
}

July 1, 2013

\author{
Roman Zakharenko \\ Higher School of Economics
}

\begin{abstract}
This paper develops a quantitative model of trade, military conflicts, and defense spending. Trade liberalization between two countries reduces probability of an armed conflict between them, causing both to cut defense spending. This in turn causes a domino effect on defense spending by other countries. As a result, both countries and the rest of the world are better off. We estimate the model using data on trade, conflicts, and military spending. We find that, after reduction of costs of trade between a pair of hostile countries, the welfare effect of worldwide defense spending cuts is comparable in magnitude to the direct welfare gains from trade.
\end{abstract}

Keywords: general equilibrium, gains from trade, defense spending JEL Codes: C5, C6, F13, F51, H56

\section{Introduction}

The traditional trade literature formulates a number of channels through which a country can gain from trade: the comparative advantage and love for variety effects, the redistribution of production factors towards more productive firms, the lower markups set by firms are some of them. In this paper, we quantitatively explore a new potential source of gains from trade. The underlying idea behind this new source of trade gains is based on recent empirical studies showing that a rise in trade between two countries reduces the probability of an armed conflict between those countries (e.g. Martin et al. (2008); Hegre et al. (2010)). Thus, if trade brings

\footnotetext{
${ }^{*}$ We are thankful to Sergey Izmalkov, Igor Muraviev, Dmitry Pervushin for useful discussions. Denis Deryushkin and Sergei Motin provided helpful research assistance.
} 
about peace, it should also bring about defense spending cuts across the world, which in turn will bring about even more peace. While in the modern world military conflicts are quite rare, countries' defense spendings are still substantial and, therefore, this additional effect of trade openness may have considerable welfare implications. In particular, we address the following questions in the paper: What is the magnitude of welfare gains due to reduced conflict probability and defense spending cuts? Is it comparable to the "traditional" gains from trade?

The quantitative model we develop is based on the following key assumptions. First, bilateral trade volumes are reduced in case of a military conflict with a certain country, leading to welfare losses. As a result, countries are less likely to be engaged in a conflict when they are connected to each other by stronger trade links. Second, the probability of having a conflict with each of potential opponents affects a country's decision on how much to spend on defense. Finally, the size of defense spending in turn has an impact on the probability of conflict with all other countries. The model thus features both causal links between trade and conflicts (conflicts reduce trade, trade prevents conflicts), as well as both causal links between conflicts and defense spending (anticipation of conflicts causes more defense spending, more defense spending makes conflicts more likely).

An important corollary of the above assumptions is that increased trade between a pair of countries will have a multiplicative effect on the global defense spending: it will cut the defense spending of not only the two trading partners, but also of other countries. Furthermore, the reduction of defense spending of other countries will have a further downward effect on the defense spending of the two trading partners. For example, increased trade between Russia and the United States should induce a reduction of defense spending of not only Russia and the United States, but also the defense spending of other potential opponents of Russia (e.g. China or Eastern European countries) and the United States (e.g. China or Venezuela); the reduction of China's defense spending would reduce the defense spending of other China's potential opponents (e.g. India), as well as further decrease of defense spending in Russia and the United States.

To assess the welfare gains of diminished conflict frequency and defense spending cuts, we need first to clarify the theoretical foundations of such welfare gains. Indeed, in a "perfect" world of full information, zero transaction costs and fully rational players, all players make decisions in such a way that aggregate welfare is maximized. Then, according to the envelope theorem, the overall marginal welfare effects of diminished trade costs are equal to the direct marginal effect, while the indirect marginal effects (via fewer conflicts and less defense 
spending) are zero. At the same time, there is a widespread belief that in a decentralized equilibrium, there are too many conflicts and too much defense spending, and an effort to reduce both is desirable; such belief is at the core of peace studies. To formalize this idea, one has to relax one or more "perfect world" assumptions. Martin et al. (2008), for example, take the asymmetric information approach: every pair of countries bargains over a joint "peace surplus" where the outside options (i.e. welfare in case of disagreement and conflict escalation) are private information. In such a setting, suboptimal conflicts may take place.

In this paper, we take another, perhaps more extreme, approach (primarily due to mathematical tractability concerns). We assume prohibitively high transaction costs of negotiation between governments and, as a result, impossibility of welfare transfers among countries. In this setting, country A may attack country B even if the welfare gains of the former are smaller than the welfare losses of the latter, rendering such an attack socially suboptimal. When strengthened trade links cause A to become more peaceful towards B, then, while the additional welfare effect of reduced hostility is zero for A due to the envelope theorem, such effect is positive for B. Moreover, such reduced hostility causes global defense spending cuts, which further improves the welfare of all countries including A.

To assess the magnitude of these additional gains from trade, we estimate the model applying the constrained maximum likelihood estimation and perform counterfactual analysis. Focusing on some of the most hostile country pairs, we quantitatively examine how unilateral trade liberalization between the two countries affects the exporter, importer, and world welfare. We find that in all experiments both exporter and importer gain from unilateral trade liberalization. Moreover, since more peaceful relations between the countries launch a worldwide wave of defense spending cuts, the rest of the world gains as well. ${ }^{1}$ For instance, a reduction in the cost of exporting from South Korea to North Korea that leads to one dollar rise in the value of exports raises the welfare of North Korea by $\$ 0.16$ (in terms of the compensating variation), the welfare of South Korea by $\$ 0.09$. At the same time, the total welfare gains of the rest of the world due to worldwide defense spending cuts are around $\$ 0.72$ (for example, the United States gain \$0.35). These numbers suggest that the world gains from trade due to defense spending cuts can be substantial, especially when the two countries involved have a history of hostility.

To the best of our knowledge, this paper is the first one that studies the interplay between trade, conflicts, and defense spending. At the same time, there exist studies of an interplay

\footnotetext{
${ }^{1}$ In the paper, we assume away the general equilibrium effects of trade liberalization that work through the adjustment of the cost of labor across countries. As a result, the only effects of unilateral trade liberalization on the rest of the world are due to worldwide defense spending cuts.
} 
of any two of these three. Substantial research, by both economists and political scientists, has been devoted to the analysis of interrelationship between trade and military conflicts. Glick and Taylor (2010) study the historic data on trade and conflicts to quantify the impact of conflicts on trade flows and on welfare. They find that conflicts reduce trade of not only the belligerent nations, but also of neutral ones, and that the impact of a conflict on trade is long-lasting and may extend well beyond the conflict itself. Martin et al. (2012) offer a theory and empirics of regional trade agreements (RTA), in which they argue that the primary benefits of RTA's include not only trade creation but also conflict prevention, and for this reason RTA's are more likely to be created in places that are more inclined to both trade and conflict, e.g. Europe. In a closely related paper, Vicard (2012) differentiates RTA's by their "depth" (i.e. extent to which the markets were integrated) and concludes that only deep enough agreements prevent conflicts. Polachek and Seiglie (2007) overviews a general theory and empirical testing methodology of the trade-conflict nexus.

To our knowledge, the only study that links trade to defense spending is Acemoglu and Yared (2010) who argue that the militarist sentiments, proxied by defense spending, lead to greater isolation of countries and thereby reduce international trade flows. In their paper, militarism and defense spending are viewed as exogenously driven by public preference. Our study makes the exact opposite assumptions: defense spending is a fully rational choice made for a purpose of welfare improvement in case of a conflict; defense spending is cut due to reduced conflict probability, which is in turn reduced by declining costs of trade.

The rest of the paper is organized as follows. Section 2 develops a theoretical framework. Section 3 describes the estimation procedure. In Section 4, the description of the data is provided. Section 5 discusses the results and performs counterfactual experiments. Section 6 concludes.

\section{The Model}

We consider a world consisting of $N$ asymmetric countries. Each country has two types of bilateral relations with the other countries: trade relations and political relations, each of which affects the utility of a representative consumer.

Political relations, which exist at the government level, are comprised of deciding whether to be in peace or in conflict with every other country. We eliminate the possibility of conflict between more than two countries due to theoretical complexity and low empirical frequency of such conflicts in the past sixty years. A military conflict occurs if at least one of the parties 
decides to initiate a conflict (to "attack"), which has an impact on countries' incomes and on the bilateral trade costs between the countries. The impact on country's income is in turn affected by the country's defense spending, which is funded through a tax on consumers.

The model of trade is based on Armington assumptions that there is perfect competition between producers of a certain country, products are distinguished by a country of origin, and individuals consume both domestic and imported varieties. Trade costs are generally exogenous, but are increased by a factor following an endogenous decision to initiate a military conflict.

The timing of events in the model is as follows. First, each country makes a defense spending and a corresponding tax level decision. Second, for every country $i$ and for every potential opponent $j \neq i$, a pair of stochastic shocks, denoted by $\epsilon_{i j}$ and $\lambda_{i j}$, is realized. The income shock, $\epsilon_{i j}$, affects the loss of income of $i$ in case of conflict with $j$, while the trade shock, $\lambda_{i j}$, affects the cost of importing from $j$ in case of the same conflict. Third, each country decides whether to attack each of its potential opponents, and peace/conflict outcomes are realized. Finally, production, trade, and consumption take place.

We describe the details of the model in the reverse chronological order.

\subsection{Consumption}

There are $N_{i}$ different varieties produced in country $i$. Following the Armington assumptions, $N_{i}$ is assumed to be exogenous. Each variety is produced in a perfectly competitive environment, resulting in the producer price of a variety in country $i$ being equal to the marginal cost of production in that country. We assume that the marginal cost of production in country $i$ is equal to the wage rate divided by the country-specific labor productivity $y_{i}$.

For analytical tractability of the model, we ignore the trade general equilibrium effects, which require exports to be equal to imports via wage adjustment. Instead, we assume that in each country $i$ the wage rate is equal to the labor productivity $y_{i}$, thus the domestic price is equal to unity. An alternative way is to introduce a homogenous freely traded good, the presence of which will assume away the general equilibrium effects on wages and, thereby, equalize the marginal cost of production across countries.

Transporting a good from country $j$ to country $i$ incurs iceberg transport costs, $\tau_{i j} \geq 1$, that are exogenous in general, but rise in case of a military conflict between $i$ and $j$, as detailed in Section 2.2.1. Thus, the price of a domestically produced variety in country $i$ is equal $\tau_{i i} \equiv 1$, while the price of a variety imported from $j$ is equal to $\tau_{i j}$. As varieties 
produced in each country are symmetric, the utility of a representative consumer in country $i$ can be written as follows:

$$
u_{i}=C_{i}\left(\sum_{j \in N} N_{j} q_{i j}^{\frac{s-1}{s}}\right)^{\frac{s}{s-1}},
$$

where $q_{i j}$ is consumption of a variety produced in $j, s>1$ is the elasticity of substitution between varieties, and $C_{i}$ is a country-specific constant, detailed in Section 3.1. The budget constraint is then

$$
\sum_{j \in N} N_{j} q_{i j} \tau_{i j} \leq e_{i},
$$

where $e_{i}$ is the disposable income of a representative consumer in country $i$.

The utility maximization problem implies that the quantity demanded of each variety is

$$
q_{i j}=\frac{e_{i} \tau_{i j}^{-s}}{\sum_{k \in N} N_{k} \tau_{i k}^{1-s}} .
$$

The indirect utility is then

$$
u_{i}=C_{i} e_{i}\left(\sum_{j \in N} N_{j} \tau_{i j}^{1-s}\right)^{\frac{1}{s-1}}=C_{i} e_{i}\left(\sum_{j \in N} T_{i j}\right)^{\frac{1}{s-1}},
$$

where $T_{i j} \equiv N_{j} \tau_{i j}^{1-s}$ is labeled as the trade propensity.

Finally, the trade volumes from $j$ to $i$ are given by

$$
X_{i j} \equiv L_{i} N_{j} q_{i j} \tau_{i j}=E_{i} \frac{T_{i j}}{\sum_{k \in N} T_{i k}},
$$

where $L_{i}$ is the population size of country $i$ and $E_{i} \equiv e_{i} L_{i}$ is the aggregate disposable income in country $i$. Assuming that the number of varieties $N_{j}$ and thus trade propensity $T_{i j}$ are proportional to the exporter economic size, the above model of trade is the simplest one that results in trade flows as predicted by the gravity equation.

\subsection{Effects of Conflicts}

In this section, we model the effects of military conflicts on trade flows and countries' disposable incomes. 


\subsubsection{Effect on Trade}

We assume that a military conflict between $i$ and $j$ increases trade costs between the two countries and, thereby, reduces the trade propensity, $T_{i j}$, by a stochastic factor. For every pair of countries $i \neq j$, we define $w_{i: j}$ as the conflict status between $i$ and $j$, endogenous to the model. ${ }^{2}$ Specifically, $w_{i: j}$ is equal to unity in case of conflict between country $i$ and $j$ and zero in case of peace.

We then define the trade propensity between $i$ and $j$, endogenous to the model, in the following way:

$$
T_{i j}=T\left(T_{i j}^{0} ; w_{i: j} ; \beta ; \lambda_{i j}\right) \equiv T_{i j}^{0} \lambda_{i j}^{w_{i: j} \bar{\lambda}} \in\left[0, T_{i j}\right],
$$

where $T_{i j}^{0}$ is the trade propensity in case of peace, $\lambda_{i j} \in[0,1]$ is a realization of the trade shock drawn from the standard uniform distribution, $\bar{\lambda}>0$ is a parameter to be estimated, and $\beta$ is the vector of the parameters in the model to be estimated, to be specified throughout section 2 , such that $\bar{\lambda} \in \beta .^{3}$ As can be seen, a military conflict between $i$ and $j$ reduces the trade propensity by a country-pair specific factor that depends on $\bar{\lambda}$ : a higher $\bar{\lambda}$ means a greater reduction of trade due to conflict.

To the best of our knowledge, we are the first ones to assume that the effect of conflict on trade is stochastic. Other studies (see, for example, Martin et al. (2008)) assume deterministic effects where trade is reduced by a constant factor. The potential heterogeneity of the effects of conflicts on trade leads to the selection problem: a conflict is more likely to happen when its effect on trade is small. Thus, if such heterogeneity is not accounted for, the model will underestimate the effects of conflicts on trade.

The above specification implies that $\bar{\lambda}$ governs both the mean and the variance of trade shocks. Ideally, we would like to estimate them separately. However, since we do not observe how much trade there would have been without a conflict, identification of both mean and variance seems complicated if not impossible. Therefore, the stochastic nature of the effect of conflict on trade is assumed rather than tested.

\footnotetext{
${ }^{2}$ Throughout the paper, semicolon is inserted between subindex elements if the corresponding link is undirected. For example, $w_{i: j} \equiv w_{j: i}$. Semicolon is not inserted for directed links, e.g. generically $T_{i j} \neq T_{j i}$.

${ }^{3}$ In the subsequent analysis, we divide all function arguments into four categories: peace-level trade propensities, country decisions (defense spending and conflicts), parameters of the model to be estimated, and realizations of shocks. The arguments of different types are separated by semicolon.
} 


\subsubsection{Effect on Income}

In the paper, we assume that the disposable income, $e_{i}$, depends on conflict statuses as well. Specifically, we define the disposable income in the following way:

$$
e_{i}=e_{i}\left(\mathbf{w}_{i}, m_{i} ; \beta ; \epsilon_{i}\right) \equiv y_{i}\left(1-m_{i}+\sigma_{i} \sum_{j \neq i} w_{i: j} Y_{j}\left(\theta \log \left(m_{i}+\alpha\right)+z_{i j} \gamma-\epsilon_{i j}\right)\right),
$$

where $\mathbf{w}_{i} \equiv\left\{w_{i: j}\right\}_{j \neq i}$ is the vector of conflict statuses with all opponents of $i ; m_{i}$ is $i$ 's defense spending as a share of its GDP; $\epsilon_{i} \equiv\left\{\epsilon_{i j}\right\}_{j \neq i}$ is the vector of income shocks drawn from the standard logistic distribution. ${ }^{4} Y_{i} \equiv y_{i} L_{i}$ is the GDP in the absence of conflicts, $z_{i j}$ is the vector of control variables affecting conflict incidence (such as the history of conflicts between the two countries, geographic and cultural distance between them, etc.). Finally, $\left\{\theta, \alpha, \gamma, \sigma_{i}\right\}_{i=1 . . N} \in \beta$ are the parameters to be estimated such that $\theta>0, \alpha>0, \sigma_{i}>0$. Notice that if $w_{i: j}$ is equal to zero for all $j \neq i$ (that is, country $i$ does not have conflicts), the disposable income is $y_{i}\left(1-m_{i}\right)$, i.e. productivity minus the defense tax.

The intuition behind (7) is as follows. Parameters $\left\{\sigma_{i}\right\}_{i=1 . . N}$ stand for the country-specific effects that govern the magnitude of income gains or losses of a country in case of conflicts. The assumption that countries choose their defense spending optimally allows us to identify $\left\{\sigma_{i}\right\}_{i=1 . . N}$ from the data. The income gains or losses are assumed to be proportional to the opponent's size, $Y_{j}$ : for Cuba, a conflict with the United States may be more costly than a conflict with the Bahamas. ${ }^{5}$ The logarithmic dependence of income on defense spending, $m_{i}$, is assumed to make $e_{i}$ concave enough with respect to $m_{i}$ and to avoid the problem of multiple local utility maxima. The parameter $\alpha$ is introduced to justify zero defense spending by some countries; it also affects the curvature of income with respect to defense spending. The logistic distribution of income shocks is chosen because (i) since income gains from conflicts range from positive values (otherwise no one would initiate a conflict) to negative ones (because most of the time, conflicts do not happen), it is desirable to have the whole real line as a support of income shocks and (ii) the logistic distribution has an analytically computable c.d.f. and the integral of c.d.f., both of which are used in the model.

All shocks in the model are assumed to be independent from each other. Identification

\footnotetext{
${ }^{4}$ By the "standard" logistic distribution, we imply a distribution with c.d.f. equal to $F(x)=\frac{e^{x}}{1+e^{x}}$.

${ }^{5}$ It is also natural to assume that welfare gains or losses of a country depend on defense spending of the opponent. However, since defense spending is endogenous in the model, this assumption would greatly complicate the analysis. The opponent's economic size, $Y_{j}$, among other things, serves as a proxy for the opponent's military potential.
} 
of correlation between shocks for the same dyad $\left(\epsilon_{i j}, \epsilon_{j i}, \lambda_{i j}, \lambda_{j i}\right)$ is impossible due to data availability; the potential correlation between shocks on different dyads sharing the same country, e.g. between $i: j$ and $i: k$, is captured, at least partially, by country fixed effects $\sigma_{i}$.

\subsection{Transformation of Utility}

With all above definitions, we can rewrite the consumer utility (4) as a function of all model ingredients:

$$
u_{i}=u\left(\mathbf{T}_{i} ; \mathbf{w}_{i}, m_{i} ; \beta ; \epsilon_{i}, \lambda_{i}\right)=C_{i} e\left(\mathbf{w}_{i}, m_{i} ; \beta ; \epsilon_{i}\right)\left(\sum_{j \in N} T\left(T_{i j}^{0} ; w_{i: j} ; \beta ; \lambda_{i j}\right)\right)^{\frac{1}{s-1}}
$$

where $\mathbf{T}_{i} \equiv\left\{T_{i j}^{0}\right\}_{j \in N}$ and $\lambda_{i} \equiv\left\{\lambda_{i j}\right\}_{j \neq i}$. Country $i$ makes a decision on its conflict status with its opponent $j, w_{i j}$, by comparing its utility from peace and from conflict with $j$. A conflict happens if at least one party finds it optimal to initiate a conflict. Typically, it is the case that at most one member of a dyad is willing to initiate a conflict. In other words, $w_{i j}$ is not necessarily equal to $w_{j i}$, implying that $w_{i: j} \equiv \max \left\{w_{i j}, w_{j i}\right\}$.

From the expression for the consumer utility in (8) it can be seen that the decision to initiate a conflict, $w_{i j}$, is interdependent with conflict statuses on other dyads $\left\{w_{i: k}\right\}_{k \neq i, j}$. This in turn makes the analysis of the model very complex. To make the model more tractable, we transform ("simplify") the utility in two steps, believing that the results will not be strongly affected.

First, we linearize the utility with respect to the conflict status vector $\mathbf{w}_{i}$, as follows:

$$
\begin{aligned}
u_{i} & \approx u\left(\mathbf{T}_{i} ; \mathbf{0}, m_{i}\right)+\sum_{j \neq i} w_{i: j}\left[u\left(\mathbf{T}_{i} ; \mathbf{1}_{j}, m_{i} ; \beta ; \epsilon_{i j}, \lambda_{i j}\right)-u\left(\mathbf{T}_{i} ; \mathbf{0}, m_{i}\right)\right] \\
& =C_{i} y_{i}\left[S_{i}\left(\mathbf{T}_{i}\right)+\sum_{j \neq i} w_{i: j}\left\{\left(1+\sigma_{i} Y_{j}\left(\theta \log \left(m_{i}+\alpha\right)+z_{i j} \gamma-\epsilon_{i j}\right)\right) S_{i j}\left(\mathbf{T}_{i} ; \beta ; \lambda_{i j}\right)-S_{i}\left(\mathbf{T}_{i}\right)\right\}\right] \\
& -C_{i} m_{i} y_{i}\left[S_{i}\left(\mathbf{T}_{i}\right)+\sum_{j \neq i} w_{i: j}\left\{S_{i j}\left(\mathbf{T}_{i} ; \beta ; \lambda_{i j}\right)-S_{i}\left(\mathbf{T}_{i}\right)\right\}\right]
\end{aligned}
$$

where $\mathbf{0}$ is a $N-1 \times 1$ vector of zeros, $\mathbf{1}_{j}$ is a vector of same size with unity corresponding to country $j$, and zeros elsewhere; $S_{i}\left(\mathbf{T}_{i}\right) \equiv\left(\sum_{j} T_{i j}^{0} \lambda_{i j}\right)^{\frac{1}{s-1}}$ is the love-of-variety component 
of utility in case of total peace, while $S_{i j}\left(\mathbf{T}_{i} ; \beta ; \lambda_{i j}\right) \equiv\left(\sum_{k \neq j} T_{i k}^{0}+T_{i j}^{0} \lambda_{i j}^{\bar{\lambda}}\right)^{\frac{1}{s-1}}$ is the same component in case of conflict with $j$ only. Note that if country $i$ has no conflicts or has a conflict with only one other country, ${ }^{6}$ the linearized utility is equal to the original utility.

In the second step, we simplify (9) further by assuming that the total cost of defense spending, as presented by the last line of (9), does not depend on the conflict incidence and is equal to $-C_{i} m_{i} y_{i} S_{i}(\cdot)$. The defense spending $m_{i}$ is typically a small fraction of GDP, while conflict incidence $w_{i: j}$ is a rare occurrence, hence the interaction between the two seems to be a negligible issue. At the same time, such simplification greatly improves the analytical tractability of the model.

Thus, we end up with the following "linearized" utility:

$$
\begin{aligned}
& u_{i}^{L}\left(\mathbf{T}_{i} ; \mathbf{w}_{i}, m_{i} ; \beta ; \epsilon_{i}, \lambda_{i}\right) \equiv C_{i} y_{i}\left(1-m_{i}\right) S_{i}\left(\mathbf{T}_{i}\right) \\
& +C_{i} y_{i} \sum_{j \neq i} w_{i: j}\left\{\left(1+\sigma_{i} Y_{j}\left(\theta \log \left(m_{i}+\alpha\right)+z_{i j} \gamma-\epsilon_{i j}\right)\right) S_{i j}\left(\mathbf{T}_{i} ; \beta ; \lambda_{i j}\right)-S_{i}\left(\mathbf{T}_{i}\right)\right\}
\end{aligned}
$$

\subsection{Attack Decisions}

In this section, we model attack decisions made by each country with respect to its potential opponents. Country $i$ decides to initiate a conflict with $j$ (in this case, $w_{i j}$ is equal to one and, therefore, $w_{i: j}$ is equal to one as well) if it is better off from doing so. In other words, the utilities under having a conflict with $j$ and without are compared. From (10), it is straightforward to see that the difference between the welfare in case of a conflict and in case of no conflict is given by (note that, due to linearization, all terms that are not relevant to the pair $\{i, j\}$ are cancelled out)

$$
u_{i}^{L}\left(\cdot ; \mathbf{1}_{j}, m_{i} ; \cdot\right)-u_{i}^{L}\left(\cdot ; \mathbf{0}, m_{i} ; \cdot\right)=C_{i} y_{i}\left\{\left(1+\sigma_{i} Y_{j}\left(\theta \log \left(m_{i}+\alpha\right)+z_{i j} \gamma-\epsilon_{i j}\right)\right) S_{i j}(\cdot)-S_{i}(\cdot)\right\}
$$

Thus, country $i$ initiates a conflict if 7

$$
\left(1+\sigma_{i} Y_{j}\left(\theta \log \left(m_{i}+\alpha\right)+z_{i j} \gamma-\epsilon_{i j}\right)\right) S_{i j}\left(\mathbf{T}_{i} ; \beta ; \lambda_{i j}\right) \geq S_{i}\left(\mathbf{T}_{i}\right)
$$

\footnotetext{
${ }^{6} \ldots$ which is true for the vast majority of country-year observations: no conflicts in 1038 out of 1629 country-year observations, one conflict in 379 cases, and more than one conflict in the remaining 212 cases.

${ }^{7}$ From a game-theoretic standpoint, there exists another equilibrium: if country $i$ is certain that it will be attacked by $j\left(w_{j i}=1\right.$ with probability one), its own decision $w_{i j}$ does not affect anything, so $i$ may choose to attack $j$ with certainty, as well, regardless of the value of $\epsilon_{i j}$. This equilibrium however is not trembling-hand-proof: if $j$ attacks $i$ with probability slightly less than one, this equilibrium falls apart. We ignore this equilibrium throughout the analysis. We thank Sergei Izmalkov for raising the issue.
} 
As can be seen, the attack decision depends on the realizations of the income shock, $\epsilon_{i j}$, and the trade shock, $\lambda_{i j}$. Specifically, the conflict takes place iff $\epsilon_{i j} \leq \epsilon_{i j}^{\star}$, where $\epsilon_{i j}^{\star}$ is the income shock cutoff given by

$$
\epsilon_{i j}^{\star}\left(\mathbf{T}_{i} ; m_{i} ; \beta ; \lambda_{i j}\right) \equiv \theta \log \left(m_{i}+\alpha\right)+z_{i j} \gamma+\frac{1}{\sigma_{i} Y_{j}}\left[1-\frac{S_{i}\left(\mathbf{T}_{i}\right)}{S_{i j}\left(\mathbf{T}_{i} ; \beta ; \lambda_{i j}\right)}\right] .
$$

The income shock cutoff increases with country $i$ 's defense spending. The greater is the defense spending, the higher the probability of initiating a conflict. The income shock cutoff decreases with the peace-level trade propensity with $j, T_{i j}^{0}$, as the losses from a conflict with $j$ are greater when there are more trade opportunities. It increases with the peace-level trade propensities with other countries, $T_{i k}^{0}$. The idea behind is that if a country trades intensively with countries other than $j$, it is less dependent on trade with $j$ and thus more likely to engage in a conflict. This relationship between trade with the rest of the world and conflict incidence has a strong empirical support (see Martin et al. (2008)).

How does the income shock cutoff depend on the opponent's size, $Y_{j}$ ? One can show that, if $j$ is a "small country" for $i$, i.e. $T_{i j}^{0}$ constitutes a small fraction of $\sum_{k} T_{i k}^{0}$, then the term in square brackets in (11) is approximately proportional to $T_{i j}^{0}$, i.e. can be presented as $k T_{i j}^{0}+o\left(T_{i j}^{0}\right)$ for some $k<0$. Assuming further that $T_{i j}^{0}$ is proportional to the exporter's economic size $Y_{j}$, we have that $\epsilon_{i j}^{\star}(\cdot)$ (marginally) does not depend on $Y_{j}$, and the opponent size (marginally) does not matter for the decision to attack them.

Note that $\epsilon_{i j}^{\star}$ is a realization of a random variable, as it depends on the realization of $\lambda_{i j}$. We can calculate the probability that $i$ initiates a conflict with $j$ as follows:

$$
P_{i j}\left(\mathbf{T}_{i} ; m_{i} ; \beta\right)=\int_{\lambda \in[0,1]} F\left(\epsilon_{i j}^{\star}\left(\mathbf{T}_{i} ; m_{i} ; \beta ; \lambda\right)\right) \mathrm{d} \lambda=\mathrm{E}_{\lambda} F\left(\epsilon_{i j}^{\star}\left(\mathbf{T}_{i} ; m_{i} ; \beta ; \lambda\right)\right),
$$

where $F(\cdot)$ is the c.d.f. of the income shock, and $\mathrm{E}_{\lambda}$ is the expectation over appropriate shocks, not to be confused with the aggregate disposable income $E_{i}$. Finally, the utility (10) can be rewritten as

$$
u_{i}^{L}\left(\mathbf{T}_{i} ; \mathbf{w}_{i}, m_{i} ; \beta ; \epsilon_{i}, \lambda_{i}\right)=C_{i} y_{i}\left(1-m_{i}\right) S_{i}\left(\mathbf{T}_{i}\right)+\sum_{j \neq i} w_{i: j} u_{i j}^{L}\left(\mathbf{T}_{i} ; m_{i} ; \beta ; \epsilon_{i j}, \lambda_{i j}\right)
$$

where

$$
u_{i j}^{L}\left(\mathbf{T}_{i} ; m_{i} ; \beta ; \epsilon_{i j}, \lambda_{i j}\right)=C_{i} y_{i} \sigma_{i} Y_{j} S_{i j}\left(\mathbf{T}_{i} ; \beta ; \lambda_{i j}\right)\left(\epsilon_{i j}^{\star}\left(\mathbf{T}_{i} ; m_{i} ; \beta ; \lambda_{i j}\right)-\epsilon_{i j}\right)
$$

is the additional utility of $i$ in case of conflict with $j$. 


\subsection{Defense Spending Decisions}

The government in each country chooses its military spending, $m_{i}$, by maximizing the expected utility, before the realizations of $\epsilon_{i j}$ and $\lambda_{i j}$ are known, and before conflict statuses are realized. The latter is equal to (irrelevant function arguments are dropped for brevity):

$$
\begin{aligned}
u_{i}^{E}(\mathbf{T} ; \mathbf{m} ; \beta) & =C_{i} y_{i}\left(1-m_{i}\right) S_{i}\left(\mathbf{T}_{i}\right) \\
& +\sum_{j \neq i}\left[P_{j i}(\cdot) \mathrm{E}_{\epsilon, \lambda} u_{i j}^{L}(\cdot ; \epsilon, \lambda)+\left(1-P_{j i}(\cdot)\right) \int_{\lambda=0}^{1} \int_{\epsilon=-\infty}^{\epsilon_{i j}^{\star}(\cdot ; \lambda)} u_{i j}^{L}(\cdot ; \epsilon, \lambda) \mathrm{d} \epsilon \mathrm{d} \lambda\right] .
\end{aligned}
$$

Here $\mathbf{T}=\left\{\mathbf{T}_{\mathbf{i}}\right\}_{i=1 . . N}$ and $\mathbf{m}=\left\{m_{i}\right\}_{i=1 . . N}$. The first term in the second line of (14) describes the expected additional utility due to possible attack by $j$. The second term in the second line of (14) represents the expected utility due to possible attack of $j$ by $i$.

Thanks to the assumption that the mean of income shock $\epsilon_{i j}$ is zero, we have the following:

$$
\mathrm{E}_{\epsilon, \lambda} u_{i j}^{L}(\cdot ; \epsilon, \lambda)=C_{i} y_{i} \sigma_{i} Y_{j} \mathrm{E}_{\lambda}\left(S_{i j}(\cdot ; \lambda) \epsilon_{i j}^{\star}(\cdot ; \lambda)\right)
$$

while

$$
\int_{\lambda=0}^{1} \int_{\epsilon=-\infty}^{\epsilon_{i j}^{\star}(\cdot ; \lambda)} u_{i j}^{L}(\cdot ; \epsilon, \lambda) \mathrm{d} \epsilon \mathrm{d} \lambda=C_{i} y_{i} \sigma_{i} Y_{j} \mathrm{E}_{\lambda}\left(S_{i j}(\cdot ; \lambda) F F\left(\epsilon_{i j}^{\star}(\cdot ; \lambda)\right)\right),
$$

where $F F(x) \equiv \int_{y \in(-\infty, x)} F(y) \mathrm{d} y$.

To determine the optimal defense spending, the government in country $i$ maximizes (14) with respect to $m_{i}$ taking $\left\{m_{j}\right\}_{j \neq i}$ as given. Given the fact that $\frac{\partial \epsilon_{i j}^{\star}\left(\mathbf{T}_{i} ; m_{i} ; \beta ; \lambda_{i}\right)}{\partial m_{i}}=\frac{\theta}{m_{i}+\alpha}$, the first derivative of (14) with respect to $m_{i}$ is given by

$$
\frac{\partial u_{i}^{E}(\mathbf{T} ; \mathbf{m} ; \beta)}{\partial m_{i}}=C_{i} y_{i}\left(\begin{array}{c}
-S_{i}\left(\mathbf{T}_{i}\right)+\frac{\sigma_{i} \theta}{m_{i}+\alpha} \sum_{j \neq i} Y_{j} P_{j i}(\cdot) \mathrm{E}_{\lambda} S_{i j}(\cdot ; \lambda) \\
+\frac{\sigma_{i} \theta}{m_{i}+\alpha} \sum_{j \neq i} Y_{j}\left(1-P_{j i}(\cdot)\right) \mathrm{E}_{\lambda} S_{i j}(\cdot ; \lambda) F\left(\epsilon_{i j}^{\star}(\cdot ; \lambda)\right)
\end{array}\right)
$$

We arrive at the following set of the first-order conditions:

$$
\frac{\partial u_{i}^{E}(\mathbf{T} ; \mathbf{m} ; \beta)}{\partial m_{i}} \begin{cases}=0, & m_{i}>0 \\ \leq 0, & m_{i}=0\end{cases}
$$

Note that, while the marginal effectiveness of defense spending, $\frac{\theta}{m_{i}+\alpha}$, decreases with $m_{i}$, the probability of a conflict increases via a rise in $\epsilon_{i j}^{\star}\left(\mathbf{T}_{i} ; m_{i} ; \beta ; \lambda_{i j}\right)$ and, therefore, the concavity of the utility with respect to $m_{i}$ is not guaranteed. While estimating the parameters, we verify the second-order conditions of optimal defense spending for all countries. 
To prevent the problem of overidentification, we assume that for countries that spent zero on defense, the parameter $\sigma_{i}$ is equal to a pre-defined value, low enough such that the constraints (16) for these countries countries hold.

For better numerical results, we modify the remaining constraints on the parameter space (16) by dividing both sides by $C_{i} y_{i} S\left(\mathbf{T}_{i}\right)>0$, adding unity, and taking logs, to arrive at the following, $\forall i: m_{i}>0$ :

$$
\begin{aligned}
G_{i}(\beta) & \equiv \log \sigma_{i}+\log \theta-\log \left(m_{i}+\alpha\right)-\log S_{i}(\cdot) \\
& +\log \left(\sum_{j \neq i} Y_{j}\left[P_{j i}(\cdot ; \beta) \mathrm{E}_{\lambda} S_{i j}(\cdot ; \beta ; \lambda)+\left(1-P_{j i}(\cdot ; \beta)\right) \mathrm{E}_{\lambda} S_{i j}(\cdot ; \beta ; \lambda) F\left(\epsilon_{i j}^{\star}(\cdot ; \beta ; \lambda)\right)\right]\right)=0
\end{aligned}
$$

By $\mathbf{G}(\beta)$ we denote the vector of all constraints described by (17).

In the above analysis, we have formulated the probability of country $j$ being attacked by country $i$ and examined its dependence on the parameters in the model (see (12)). We have also established the conditions that determine the choice of military spending made by countries, (17). The proposed framework has several empirically plausible properties that are at the core of the analyzed model:

- Countries spend more on defense if a conflict is more likely. This follows from the fact that the optimal $m_{i}$ solving (17) rises with $P_{j i}$ and with $\epsilon_{i j}^{\star}$. Conversely, a conflict is more likely if countries spend more on defense. That is, $P_{i j}$ rises with $m_{i}$.

- A rise in the defense spending of a certain country increases the probability of a conflict with its opponents and, therefore, increases the defense spending of all other countries. In other words, an arms race takes place.

- Greater trade volumes result in larger welfare losses in case of conflict making military conflicts less likely. That is, $P_{i j}$ decreases with $T_{i j}$.

In the next section, we fit the model to the data on bilateral military conflicts, countries' military spending, and bilateral trade volumes. 


\section{Fitting Model to Data}

\subsection{Calibration}

We borrow the value for the elasticity of substitution, $s$, from the existing trade literature. Specifically, we choose $s=4$, which is the mean value of the elasticities estimated in Broda and Weinstein (2006).

The peace-level trade propensities $T_{i j}^{0}$ were calibrated as follows. First, from (5), it follows that $\frac{T_{i j}^{0}}{T_{i k}^{0}}=\frac{X_{i j}^{0}}{X_{i k}^{0}}$, where $X_{i j}^{0}$ are trade volumes that would prevail in case of total peace. In other words, the ratio of trade propensities equals the ratio of trade volumes, $\forall i, j, k$. Second, the level of trade propensities is immaterial: multiplying $T_{i j}^{0}, \forall j$ by some importerspecific constant $k_{i}$ will not change any results in the model. For this reason, we choose the benchmark level of trade propensities such that they are numerically equal to peace-level trade volumes $X_{i j}^{0}$, i.e. $T_{i j}^{0}=X_{i j}^{0}, \forall i, j$.

To meet the budget-balancedness condition $\sum_{j} X_{i j}^{0}=E_{i}=\left(1-m_{i}\right) Y_{i}$, that the totalpeace-level expenditure on goods imported from all countries (including domestically produced goods) equals the total-peace-level disposable income, we set the "self-trade" propensity equal to the difference between the disposable income and the sum of imports: $T_{i i}^{0}=$ $\left(1-m_{i}\right) Y_{i}-\sum_{j \neq i} X_{i j}^{0}$.

One difficulty in the above calibration is that we do not observe the total-peace-level trade volumes $X_{i j}^{0}$; we only know the actual trade volumes $\hat{X}_{i j}$. For countries that had no conflicts in a given year, the two are equal to each other, while for other countries we have that $X_{i j}^{0}>\hat{X}_{i j}$ if $\hat{w}_{i: j}>0$, and $X_{i j}^{0}<\hat{X}_{i j}$ if $\hat{w}_{i: j}=0$. Given the stochastic nature of the trade shocks, there is no way to determine $X_{i j}^{0}$ precisely, even if the trade shock parameter $\bar{\lambda}$ is known. Throughout the analysis, we employ the most simple calibration method: we simply set $X_{i j}^{0}=\hat{X}_{i j}$.

The productivity of a country $Y_{i}$ is set equal to its observed GDP $\hat{Y}_{i}$. For countries that actually had conflicts, such calibration has an obvious shortcoming, since throughout the model we assume that conflicts move the actual realization of income away from the peace-level productivity $Y_{j}$. Thus, we sacrifice some realism for the sake of mathematical tractability of the model.

Finally, the utility scale parameter $C_{i}$ is chosen such $C_{i} S_{i}\left(\mathbf{T}_{i}\right)=1$. This way, the utility in case of peace among all countries is numerically equal to disposable income $e_{i}$, thus a utility change due to changing model parameters is numerically equal to the compensating variation of income. For this reason, in the policy experiment section of this paper, all 
marginal changes in utility due to changing trade costs are nominated in dollars.

\subsection{Estimation}

The set of parameters in the model we estimate is $\beta=\left(\theta, \alpha, \bar{\lambda}, \gamma,\left\{\sigma_{i}\right\}_{i=1 . . N}\right)$. We estimate the unknown parameters using the maximum likelihood estimator with constraints on the parameter space. In particular, we fit the predicted probabilities of conflict initiation (12) to actually observed conflict initiation status. In doing so, we account for a discrepancy between the theoretical model and the actually available data. Specifically, the theoretical model predicts that a pair of countries $i$ and $j$ decide independently whether or not to attack each other, meaning that it is possible that both may decide to attack $\left(w_{i j}=w_{j i}=1\right)$. In the data however, as described in detail in section 4 , only one side may be a conflict initiator, thus $\hat{w}_{i j}+\hat{w}_{j i} \leq 1$, where $\hat{w}_{i j}$ and $\hat{w}_{j i}$ are observed in the data conflict initiation statuses. To reconcile the discrepancy, we assume that, if both countries decide to attack, each of them becomes the "observed" attacker with probability $\frac{1}{2}$. With this assumption, the theoretical probabilities of observed outcomes are as follows (dropping some function arguments):

$$
\begin{aligned}
& \operatorname{Pr}\left(\hat{w}_{i j}=0, \hat{w}_{j i}=0\right)=\left(1-P_{i j}(\cdot ; \beta)\right)\left(1-P_{j i}(\cdot ; \beta)\right), \\
& \operatorname{Pr}\left(\hat{w}_{i j}=1, \hat{w}_{j i}=0\right)=P_{i j}(\cdot ; \beta)\left(1-P_{j i}(\cdot ; \beta)\right)+\frac{1}{2} P_{i j}(\cdot ; \beta) P_{j i}(\cdot ; \beta), \\
& \operatorname{Pr}\left(\hat{w}_{i j}=0, \hat{w}_{j i}=1\right)=\left(1-P_{i j}(\cdot ; \beta)\right) P_{j i}(\cdot ; \beta)+\frac{1}{2} P_{i j}(\cdot ; \beta) P_{j i}(\cdot ; \beta) .
\end{aligned}
$$

The corresponding loglikelihood function can be then written as follows:

$\mathcal{L}(\beta)=\sum_{i} \sum_{j \neq i}\left\{\hat{w}_{i j} \log \left(P_{i j}(\cdot ; \beta)\right)+\hat{w}_{j i} \log \left(1-\frac{1}{2} P_{i j}(\cdot ; \beta)\right)+\left(1-\hat{w}_{i j}-\hat{w}_{j i}\right) \log \left(1-P_{i j}(\cdot ; \beta)\right)\right\}$.

Since in the model country's military spending is endogenous and chosen to maximize its expected utility function, we use the conditions implied by (17), for countries with positive defense spending, as restrictions on the parameter space in the estimation procedure. In this case, the estimate of $\beta$ is

$$
\hat{\beta}=\arg \max _{\tilde{\beta}} \mathcal{L}(\tilde{\beta})
$$

subject to (17) and to zero lower bounds on $\theta, \alpha$, and $\sigma_{i}$. Appendix A details the computational algorithm and the asymptotic variance of the estimate.

The identification of $\theta$ and $\alpha$ comes from the relationship between conflict incidence 
and military spending in the data. Parameter $\bar{\lambda}$ is identified from the relationship between military conflict incidence and trade volumes found in the data (see, for instance, Martin et al. (2008)). Finally, $\left\{\sigma_{i}\right\}, \forall i: m_{i}>0$ can be identified due to the presence of the constraints in the estimation procedure.

\subsection{Additional Adjustments}

The availability of data suggests some adjustments to the theoretical model and to the estimation method described above.

First, given the availability of data on multiple years, we use them all while estimating the parameters in the model. We treat observations from different years as independent ones and ignore potential autocorrelation of shocks for the following reasons: (i) while ignored autocorrelation leads to inconsistent short-term predictions, it does not compromise longterm effects that are our primary goal, (ii) autocorrelation of shocks would complicate the model beyond reason, especially given the discrete nature of the dependent variable.

Second, given the availability of data on conflict dates, we can expand the support of $\hat{w}_{i j}$ from $\{0,1\}$ (conflict, no conflict) to the entire unit interval (fraction of the year with active conflict). Intuitively, a conflict that lasted one day has a smaller effect on trade than a conflict that lasted the entire year. Empirically, there is indeed a strong correlation between conflict length and trade (for those observations with $w_{i: j}>0$ ). While such adjustment does not require any changes in the estimation procedure, it does require some theoretical justification. To justify intermediate values of $\hat{w}_{i j}$, we assume that shocks in the model are realized every day rather than once per year, and every country $i$ updates every day its decision of whether to be in conflict with every other country $j$.

To make sure that the first-order conditions of optimal defense (16) hold for any country in any given year, we allowed the parameters $\sigma_{i}$ to vary across years, effectively making them country-year fixed effects.

Most expectations in the model over $\lambda$ are not computable analytically and had to be approximated numerically. To do so, we define a grid of points for $\lambda$, such that the change of c.d.f. between any two consecutive points is the same, and approximate the integral by the average value of the integrand across the grid points. The number of grid points was driven by computer memory constraints and set equal to 25 . 


\section{Data}

In this section, we describe the data we use to estimate the model. We have dropped several countries due to data availability concerns; the full list is provided in Appendix B.1. The remaining sample consists of 181 countries, observed in 9 years as detailed below.

\subsection{Conflicts}

Our primary source of data is the dyadic Militarized Interstate Dispute dataset, version 3.10 (Ghosen et al., 2004). The dataset provides the list of all "militarized interstate disputes": i.e., "conflicts in which one or more states threaten, display, or use force against one or more other states" for years 1993-2001. For each conflict, the dataset includes the list of all country pairs which had a hostility between each other. For every such country pair, we use information on the start and end dates of the hostility, the level of hostility on a scale from 1 to 5 , and a flag for the initiator of the conflict.

Following Martin et al. (2008), by a "conflict" we consider only conflicts with hostility level of 3 (Display of Force) and above (Use of Force, War) - overall, 483 out of 512 conflict observations meet this criterion. The empirical conflict status $\hat{w}_{i j}$ is computed as fraction of the year that $i$ and $j$ were in a conflict, such that $i$ was the conflict originator (in the data, one and only one member of a dyad may be an originator).

\subsection{GDP}

The gross domestic product is measured in current U.S. dollars. The data is from the World Development Indicators of the World Bank. The missing observations were filled by data from IMF's World Economic Outlook. For North Korea which had no GDP data in any year, we employed the 1991 estimate of 22.9 billion USD, given in the Wikipedia article "Economy of North Korea." The observations that were still missing were replaced by values predicted by the regression

$$
\log \left(\frac{\mathrm{GDP}_{i t}}{L_{i t}}\right)=\delta_{0}+\delta_{1} \log \left(\frac{\mathrm{PEC}_{i t}}{L_{i t}}\right)+\delta_{i}+\delta_{t}+\nu_{i t}
$$

where $\mathrm{PEC}_{i t}$ is Primary Energy Consumption as reported by National Material Capabilities dataset, version 4.0 (Singer et al., 1972); $\delta_{i}$ is the country fixed effect, $\delta_{t}$ is the year fixed effect, $\nu_{i t}$ is the residual, and year $t$ ranges from 1981 to 2007. 


\subsection{Defense Spending}

The primary source of information on defense spending is Stockholm International Peace Research Institute (SIPRI), which reports such spending as a share of GDP for a wide range of countries and years. The missing data was filled by the calculated ratio of defense expenditure to GDP, where the former is taken from above mentioned National Material Capabilities dataset. The correlation between the two sources is approximately $66 \%$.

For some country-year observations, e.g. Cuba in 1993, defense spending observations were missing. Out of $181 \times 9=1629$ country-year observations, 45 had such missing defense data. We illustrate the handling of such observations by continuing the Cuba example. To calculate the probability that Cuba attacks other countries in 1993, zero defense spending was assumed; such probability however was only used to fit the constraint (16) for countries other than Cuba; it was excluded from the loglikelihood function (18).

As mentioned earlier, we also do not verity the first-order condition (16) for countries that spend zero on defense (as well as for countries with missing defense data), and a corresponding $\sigma_{i}$ is assumed equal to a default value. In all, we have 1490 out of 1629 country-year observations with positive defense spending, each accompanied by an unknown value of $\sigma_{i}$ and by a constraint (17).

\subsection{Trade}

The primary source of trade data is Bilateral Trade dataset, version 3.0, by Barbieri and Pollins (2009). The missing data was filled using Feenstra et al. (2005), with correlation between the two sources exceeding $99 \%$. While calculating the attack probability, the missing observations were replaced by zeros. However, if a trade data $\hat{X}_{i j}$ was missing, the corresponding attack probability $P_{i j}$ was dropped from the loglikelihood function (18). In all, 46280 country-country-year observations out of $181 \times 180 \times 9=293220$ had missing data on trade.

After excluding missing trade and defense data, 239528 country-country-year observations out of 293220 were included into the loglikelihood function.

\subsection{Control Variables}

Besides the constant, there are four sets of control variables: conflict history, contiguity, other distance variables, year fixed effects. Below we describe the first three. 


\subsubsection{Conflict History}

A major predictor of conflicts between a pair of countries is preceding history of conflicts between them. The history of conflicts between countries $i$ and $j$ is measured as the total length of conflicts of hostility levels 3-5 between years 1951 and 1992, as reported by Militarized Interstate Dispute dataset, version 2.0 (Zeev, 2005). Since the political map of the world has considerably changed in the early 1990s, a number of adjustments had to be made. Conflicts between countries that later merged into one (e.g. between Federal Republic of Germany and German Democratic Republic) were dropped. Conflicts between such countries and third countries were added to the history of conflicts of their successors (e.g. a conflict between GDR and USA contributed to a history of conflicts between modern Germany and USA).

To account for possible nonlinear effects of past conflicts on modern conflicts, we add conflict history squared to the set of control variables.

\subsubsection{Contiguity}

The data on geographic contiguity in taken from Direct Contiguity dataset, version 3.10 (Stinnett et al., 2002). The dataset identifies five types of contiguity, from most proximate type-1 (countries separated by a land or river border) to most distant type- 5 (countries separated by 150-400 miles of water); we include a dummy for each of the five contiguity types.

\subsubsection{Other Distance Variables}

An additional source of information on distance, both geographic and cultural, is the GeoDist database (Mayer and Zignago, 2011). We use the following variables from the dataset: log of (population-weighted) geographic distance between countries, a dummy for common official language, a dummy for common language for $9 \%$ of population in both countries, a dummy for colonial link ever between the two countries, and a dummy for a pair of countries having a common colonizer after 1945 .

\section{Results}

In this section, we present the results of the estimation procedure and perform counterfactual analysis. 


\subsection{The Parameter Estimates}

The parameter estimates are reported in Table 1. Note that we have estimated the values of $\operatorname{logs}$ of $\theta, \alpha$, and $\sigma_{i}$, because these parameters must be positive. The following control variables are significant: history of conflicts and its square, contiguity of types 1 and 2, distance between countries, linguistic and colonial links. Almost all significant parameters have the expected sign: the effect of conflict history on conflict incidence is positive and concave, the effect of geographic proximity is positive, the effect of linguistic proximity is negative, while almost all measures of past political ties have a positive effect on conflict incidence.

The estimate of $\bar{\lambda}$ implies that a conflict reduces trade, on average, by a factor of 3.6. ${ }^{8}$ The estimate of $\alpha$ implies that the marginal product of defense spending by a country that spends nothing on defense is almost 50 times higher than that of a country that spends on defense $5 \%$ of its GDP; such sharp concavity of welfare with respect to defense spending ensured the second-order condition of optimal defense spending for every country-year observation.

Given the estimates, for any country we can calculate the probability of being attacked by any other country in any given year. The highest such probability was $72.95 \%$, that North Korea attacks South Korea in 1994, while the lowest probability in the order of $10^{-289}$, that Kiribati attacks Fiji in $2001 .^{9}$ Overall, the predicted probabilities are consistent with subjective expectations. For example, for the United States in 2001, the greatest threats of attack came from Russia $(2.92 \%),{ }^{10}$ North Korea $(1.75 \%)$, and China $(0.70 \%)$. For Israel in 2001, the top threats were Jordan (31.84\%), Lebanon (11.72\%), and Egypt (6.36\%). ${ }^{11}$

\subsection{Counterfactuals}

With these results, we ask the primary question of the paper - how increased trade affects conflicts and defense spending. For that purpose, we define a counterfactual experiment as follows: reduced trade costs $\tau_{i j}$ and a corresponding increase of trade propensity $T_{i j}^{0}$ such that the total-peace level of trade $X_{i j}^{0}$ increases by one dollar, assuming constant defense spending and constant trade propensities on other dyads. Note that, due to the substitution

\footnotetext{
${ }^{8}$ As mentioned earlier, the observed effect of conflicts on trade is smaller due to selection: a conflict is more likely to occur if it causes less harm to trade.

${ }^{9} \mathrm{Such}$ extremely low estimate is due to the fact that Kiribati has no military force, had no conflict history with Fiji; at the same time, there are strong economic ties: in year 2001, the recorded volume of imports from Fiji to Kiribati accounted for $15 \%$ of GDP of the latter.

${ }^{10}$ The high estimate is based on a long history of conflicts between Russia and the USA.

${ }^{11}$ Palestine was not included into the data, thus the Palestinian threat for Israel was not accounted for.
} 
Table 1: Estimates of the model parameters

\begin{tabular}{ll}
\hline Parameter & Estimate (Std.Err.) \\
\hline $\log \theta$ & $-0.5589(0.2145)$ \\
$\log \alpha$ & $-6.4788(1.7614)$ \\
$\bar{\lambda}$ & $2.6930(2.6237)$ \\
constant & $-1.1777(0.9933)$ \\
conflict history & $0.4098(0.0339)$ \\
history squared & $-0.0101(0.0013)$ \\
type-1 contiguity & $1.9113(0.2629)$ \\
type-2 contiguity & $2.3280(0.4302)$ \\
type-3 contiguity & $0.0421(1.8419)$ \\
type-4 contiguity & $0.9699(0.5236)$ \\
type-5 contiguity & $0.2641(0.5328)$ \\
log weighted distance & $-0.6755(0.1014)$ \\
common official language & $0.7360(0.2502)$ \\
common language for $9 \%$ of pop in both countries & $-0.5479(0.2662)$ \\
colonial link ever & $1.5200(0.2433)$ \\
common colonizer after 1945 & $-0.5923(0.2494)$ \\
year fixed effects & yes \\
$\sigma_{i}$ & yes \\
$\#$ of observations & 239528 \\
loglikelihood & -1113.91 \\
\hline
\end{tabular}


effect, a rise of trade propensity $T_{i j}^{0}$ causes imports to $i$ from countries other than $j$ to drop.

Using the assumption that the initial peace-level trade propensity $T_{i j}^{0}$ is numerically equal to $X_{i j}^{0}$, and taking into account (5), we can show that the new peace-level trade propensity is $T_{i j}^{1}=T_{i j}^{0}+\Delta T$, where $\Delta T \equiv \frac{\sum_{k} T_{i k}^{0}}{\sum_{k \neq j} T_{i k}^{0}}=\frac{E_{i}}{E_{i}-T_{i j}^{0}}$ is considered to be a marginal change in trade volume. We can also show that the new peace-level trade volumes are $X_{i j}^{1}=X_{i j}^{0}+1+o(\Delta T)$, as defined, and that $X_{i k}^{1}=X_{i k}^{0}-\frac{X_{i k}^{0}}{E_{i}-X_{i j}^{0}}+o(\Delta T), \forall k \neq j .{ }^{12}$

In the present paper, we report the results of three counterfactual experiments. In experiment $\# 1$, the importer (country $i$ ) is Jordan and the exporter (country $j$ ) is Israel. In experiment \#2, the importer is North Korea and the exporter is South Korea. In experiment \#3, the importer is Russia and the exporter is the United States of America. In all three cases, the experiment year was 2001, the last year of available data.

Next, we outline the effects of such trade cost changes.

\subsubsection{Effects on defense spending}

The change in defense spending by each country can be calculated by totally differentiating the first-order condition of optimal defense spending given by (16) with respect to $\mathbf{m}$ and $T_{i j}$ and by solving for the vector of $\frac{\partial m_{k}}{\partial T_{i j}}$ :

$$
\left(\begin{array}{c}
\mathrm{d} m_{1} \\
\cdots \\
\mathrm{d} m_{N}
\end{array}\right)=-\left(\begin{array}{ccc}
\frac{\partial^{2} u_{1}^{E}}{\partial m_{1}^{2}} & \cdots & \frac{\partial^{2} u_{1}^{E}}{\partial m_{1} \partial m_{N}} \\
\cdots & \cdots & \cdots \\
\frac{\partial^{2} u_{N}^{E}}{\partial m_{N} \partial m_{1}} & \cdots & \frac{\partial^{2} u_{N}^{E}}{\partial m_{N}^{2}}
\end{array}\right)^{-1}\left(\begin{array}{c}
\frac{\partial^{2} u_{1}^{E}}{\partial m_{1} \partial T_{i j}} \\
\ldots \\
\frac{\partial^{2} u_{N}^{E}}{\partial m_{N} \partial T_{i j}}
\end{array}\right) \Delta T
$$

Since the typical response to reduced trade costs is reduction (rather than increase) of defense spending worldwide, and since the natural lower bound on defense spending is zero, countries that already spent zero on defense were not allowed to adjust their spending.

Tables 2, 3, 4 report defense spending cuts by various countries in the two specified experiments. The standard errors of the estimates are due to the standard errors of the estimated model parameters. In all three experiments, the United States and the United Kingdom were among the top respondents to changing political arena, which is a consequence of high involvement of both into global political affairs. Also in all three experiments, the exporter (Israel, South Korea, and the USA, respectively) shows a stronger defense spending response to changing trade costs than the importer.

\footnotetext{
${ }^{12}$ To show the result for $X_{i j}^{1}$, observe that $X_{i j}^{1}=E_{i} \frac{T_{i j}^{0}+\Delta T}{E_{i}+\Delta T}$, thus $X_{i j}^{1}-X_{i j}^{0}=\frac{\left(E_{i}-T_{i j}^{0}\right) \Delta T}{E_{i}+\Delta T}=\frac{E_{i}}{E_{i}+\Delta T}=$ $1+o(\Delta T)$. Likewise, we can show the result for $X_{i k}^{1}, k \neq j$.
} 
Table 2: Defense spending cuts by selected countries following reduction of costs of imports to Jordan from Israel in 2001.

\begin{tabular}{ll}
\hline Country & Defense spending change, \$ (Std.Err.) \\
\hline United States of America & $-0.0039(0.0039)$ \\
United Kingdom & $-0.0030(0.0026)$ \\
Italy & $-0.0011(0.0010)$ \\
Egypt & $-0.0056(0.0040)$ \\
Lebanon & $-0.0018(0.0014)$ \\
Jordan & $-0.0419(0.0135)$ \\
Israel & $-0.0861(0.0411)$ \\
Saudi Arabia & $-0.0098(0.0072)$ \\
WORLD & $-0.1633(0.0776)$ \\
\hline
\end{tabular}

Table 3: Defense spending cuts by selected countries following reduction of costs of imports to North Korea from South Korea in 2001.

\begin{tabular}{ll}
\hline Country & Defense spending change, \$ (Std.Err.) \\
\hline United States of America & $-0.0593(0.0469)$ \\
United Kingdom & $-0.0022(0.0023)$ \\
France & $-0.0014(0.0016)$ \\
Russia & $-0.0011(0.0012)$ \\
China & $-0.0037(0.0036)$ \\
North Korea & $-0.0567(0.0219)$ \\
South Korea & $-0.0390(0.0275)$ \\
Japan & $-0.0286(0.0269)$ \\
WORLD & $-0.2053(0.1336)$ \\
\hline
\end{tabular}

Table 4: Defense spending cuts by selected countries following reduction of costs of imports to Russia from the United States of America in 2001.

\begin{tabular}{ll}
\hline Country & Defense spending change, \$ (Std.Err.) \\
\hline United States of America & $-0.1366(0.0978)$ \\
Canada & $-0.0016(0.0016)$ \\
United Kingdom & $-0.0037(0.0036)$ \\
France & $-0.0021(0.0022)$ \\
Germany & $-0.0012(0.0013)$ \\
Italy & $-0.0011(0.0012)$ \\
Russia & $-0.0170(0.0058)$ \\
China & $-0.0030(0.0027)$ \\
Japan & $-0.0122(0.0097)$ \\
WORLD & $-0.1906(0.1350)$ \\
\hline
\end{tabular}




\subsubsection{Welfare Implications}

Below we propose a classification of all welfare effects of increasing $T_{i j}^{0}$ on the "aggregate" expected utility $L_{k} u_{k}^{E}, \forall k$. In formulas below, we show the marginal effects, to be multiplied by a factor of $\Delta T$. The expected welfare is affected both directly and via changing defense spending; moreover, the direct welfare effect for the importer $i$ is qualitatively different from that for all other countries. For this reason, we divide welfare effects into three groups: direct effect for importer, direct effect for other countries, and indirect effect via changing defense spending for all countries.

- Direct effect on the importer. Following a decrease in trade costs and associated rise in trade propensity $T_{i j}^{0}$, the importer $i$ experiences, among other things, an expansion of the opportunity set, changed expected welfare due to possible attack by neighbors, and changed expected welfare due to possible own attack on neighbors. In math,

$$
\begin{aligned}
& \frac{L_{i} \partial u_{i}^{E}(\mathbf{T} ; \mathbf{m} ; \beta)}{\partial T_{i j}^{0}}=C_{i} Y_{i}\left(1-m_{i}\right) \frac{\partial S_{i}\left(\mathbf{T}_{i}\right)}{\partial T_{i j}^{0}} \\
& +C_{i} Y_{i} \sigma_{i} \sum_{k \neq i} Y_{k} P_{k i}(\cdot) \mathrm{E}_{\lambda}\left(\frac{\partial S_{i k}\left(\mathbf{T}_{i} ; \beta ; \lambda\right)}{\partial T_{i j}^{0}} \epsilon_{i k}^{\star}(\cdot ; \lambda)+S_{i k}(\cdot ; \lambda) \frac{\partial \epsilon_{i k}^{\star}\left(\mathbf{T}_{i} ; \cdot ; \lambda\right)}{\partial T_{i j}^{0}}\right) \\
& +C_{i} Y_{i} \sigma_{i} \sum_{k \neq i} Y_{k}\left(1-P_{k i}(\cdot)\right) \mathrm{E}_{\lambda}\left(\frac{\partial S_{i k}\left(\mathbf{T}_{i} ; \beta ; \lambda\right)}{\partial T_{i j}^{0}} F F\left(\epsilon_{i k}^{\star}(\cdot ; \lambda)\right)+S_{i k}(\cdot ; \lambda) \frac{\partial \epsilon_{i k}^{\star}\left(\mathbf{T}_{i} ; \cdot ; \lambda\right)}{\partial T_{i j}^{0}} F\left(\epsilon_{i k}^{\star}(\cdot ; \lambda)\right)\right)
\end{aligned}
$$

Due to the assumptions made in Section 3.1, the first line in (19) is merely $\frac{1}{s-1}$, and is equal to the love of variety welfare effect equivalent to that of conventional trade models. It is the only effect that exists even in the absence of conflicts. The second line of (19) is the change in utility associated with conflicts initiated by neighbors of $i$. Finally, the third line of (19) is the change in utility associated with conflicts initiated by $i$ itself. Note that the second and the third lines are typically negative for $k=j$, as they reflect by how much the gains from trade are reduced by possible conflict incidence.

- Peaceful importer effect. Changing trade patterns make the importer $i$ more dependent on the exporter $j$, which reduces the probability that $i$ attacks $j$. Thereby, $j$ 's expected welfare is increasing, which is labeled as peaceful importer effect. Note that substitution of trade flows causes $i$ to import less from other exporters $k \neq i, j$ and thereby makes $i$ more hostile towards $k$. Thus, the peaceful importer effect for $k \neq i, j$ 
is negative. The peaceful importer effect does not apply to the importer $i$ itself. In math, the peaceful importer effect is equal to (dropping function arguments)

$$
\frac{L_{k} \partial u_{k}^{E}}{\partial T_{i j}}=C_{k} Y_{k} \sigma_{k} Y_{i} \frac{\partial P_{i k}\left(\mathbf{T}_{i} ; \cdot\right)}{\partial T_{i j}} \mathrm{E}_{\lambda} S_{k i}(\cdot ; \lambda)\left(\epsilon_{k i}^{\star}(\cdot ; \lambda)-F F\left(\epsilon_{k i}^{\star}(\cdot ; \lambda)\right)\right) .
$$

- Defense spending cuts by neighbors. Reduced hostility of $i$ towards $j$ causes both $i$ and $j$ to cut their defense spending, which makes both less hostile towards each other and towards third countries, which causes further defense spending cuts worldwide. While the welfare effect of own defense spending cuts is zero due to the envelope theorem, the effect of neighbors' cuts is positive. In math, the welfare effect of defense spending cuts by neighbors for country $k$ is equal to

$$
L_{k} \sum_{n} \frac{\partial u_{k}^{E}(\mathbf{T} ; \mathbf{m} ; \beta)}{\partial m_{n}} \frac{\partial m_{n}}{\partial T_{i j}}
$$

where

$$
\frac{\partial u_{k}^{E}}{\partial m_{n}}=C_{k} Y_{k} \sigma_{k} Y_{n} \frac{\partial P_{n k}\left(\cdot ; m_{n} ; \cdot\right)}{\partial m_{n}} \mathrm{E}_{\lambda} S_{k n}(\cdot ; \lambda)\left(\epsilon_{k n}^{\star}(\cdot ; \lambda)-F F\left(\epsilon_{k n}^{\star}(\cdot ; \lambda)\right)\right)
$$

Tables 5, 6, 7 report the welfare effects for the three experiments of this paper. The defense cuts by neighbors effect is truly global. In all three experiments, Brazil is thousands of kilometers away from both exporters and importers, but is one of top beneficiaries, primarily due to defense cuts by the United States which is highly involved in global affairs.

The three experiments show that declining defense spending may account for a half or more of all welfare effects of declining trade costs, so we can conclude that the defense spending consequences of changing trade costs cannot be ignored.

We can also split the defense cuts by neighbors effect by every particular neighbor. For example, in the Korean experiment (Table 6), the American welfare gain of $\$ 0.3511$ includes $\$ 0.0042$ due to defense spending cuts by Canada, $\$ 0.0015$ due to Mexico, $\$ 0.0033$ due to the United Kingdom, \$0.0017 due to France, $\$ 0.0176$ due to Russia, \$0.0344 due to China, $\$ 0.2672$ due to defense spending cuts by North Korea, \$0.0061 due to South Korea, and $\$ 0.0108$ due to Japan. Furthermore, the American welfare gain of $\$ 0.2672$ due to defense cuts by North Korea is the product of $\$ 4.7088$ of American welfare gain per dollar of North Korean defense spending cut, times the $\$ 0.0567$ of the magnitude of such cut (as shown in Table 3). Furthermore, the marginal American welfare gain of $\$ 4.7088$ due to North Korean 
Table 5: Welfare effects for selected countries following reduction of costs of imports to Jordan from Israel in 2001.

\begin{tabular}{|c|c|}
\hline Country & Welfare effect, \$ (Std.Err.) \\
\hline \multicolumn{2}{|c|}{ Direct effect on importer } \\
\hline Jordan & $0.1698(0.0504)$ \\
\hline \multicolumn{2}{|c|}{ Peaceful importer effect } \\
\hline Israel & $0.1336(0.0458)$ \\
\hline \multicolumn{2}{|c|}{ Defense cuts by neighbors } \\
\hline Unites States of America & $0.0369(0.0257)$ \\
\hline Canada & $0.0013(0.0011)$ \\
\hline Mexico & $0.0011(0.0010)$ \\
\hline Colombia & $0.0012(0.0008)$ \\
\hline Venezuela & $0.0010(0.0007)$ \\
\hline Brazil & $0.0061(0.0039)$ \\
\hline Argentina & $0.0017(0.0013)$ \\
\hline United Kingdom & $0.0247(0.0146)$ \\
\hline Netherlands & $0.0018(0.0013)$ \\
\hline France & $0.0066(0.0045)$ \\
\hline Spain & $0.0032(0.0024)$ \\
\hline Portugal & $0.0012(0.0008)$ \\
\hline Germany & $0.0085(0.0061)$ \\
\hline Italy & $0.0102(0.0066)$ \\
\hline Greece & $0.0012(0.0007)$ \\
\hline Sweden & $0.0016(0.0010)$ \\
\hline Norway & $0.0015(0.0010)$ \\
\hline South Africa & $0.0014(0.0009)$ \\
\hline Iran & $0.0023(0.0014)$ \\
\hline Turkey & $0.0035(0.0022)$ \\
\hline Egypt & $0.0238(0.0130)$ \\
\hline Syria & $0.0039(0.0018)$ \\
\hline Lebanon & $0.0058(0.0032)$ \\
\hline Jordan & $0.0018(0.0011)$ \\
\hline Israel & $0.0344(0.0193)$ \\
\hline Saudi Arabia & $0.0484(0.0214)$ \\
\hline Kuwait & $0.0017(0.0010)$ \\
\hline United Arab Emirates & $0.0043(0.0025)$ \\
\hline Oman & $0.0011(0.0006)$ \\
\hline China & $0.0011(0.0010)$ \\
\hline Japan & $0.0068(0.0052)$ \\
\hline Singapore & $0.0012(0.0008)$ \\
\hline Australia & $0.0021(0.0015)$ \\
\hline WORLD & $0.2777(0.1542)$ \\
\hline \multicolumn{2}{|c|}{ All effects combined } \\
\hline WORLD & $0.5787(0.1765)$ \\
\hline
\end{tabular}


Table 6: Welfare effects for selected countries following reduction of costs of imports to North Korea from South Korea in 2001.

\begin{tabular}{|c|c|}
\hline Country & Welfare effect, \$ (Std.Err.) \\
\hline \multicolumn{2}{|c|}{ Direct effect on importer } \\
\hline North Korea & $0.1581(0.0552)$ \\
\hline \multicolumn{2}{|c|}{ Peaceful importer effect } \\
\hline South Korea & $0.0682(0.0375)$ \\
\hline Japan & $-0.0014(0.0010)$ \\
\hline \multicolumn{2}{|c|}{ Defense cuts by neighbors } \\
\hline United States of America & $0.3511(0.2000)$ \\
\hline Canada & $0.0069(0.0061)$ \\
\hline Mexico & $0.0048(0.0047)$ \\
\hline Colombia & $0.0022(0.0016)$ \\
\hline Venezuela & $0.0016(0.0013)$ \\
\hline Brazil & $0.0089(0.0071)$ \\
\hline Argentina & $0.0024(0.0021)$ \\
\hline United Kingdom & $0.0195(0.0154)$ \\
\hline Netherlands & $0.0022(0.0019)$ \\
\hline France & $0.0123(0.0098)$ \\
\hline Spain & $0.0046(0.0041)$ \\
\hline Portugal & $0.0014(0.0011)$ \\
\hline Germany & $0.0092(0.0082)$ \\
\hline Italy & $0.0093(0.0077)$ \\
\hline Russia & $0.0050(0.0040)$ \\
\hline Sweden & $0.0018(0.0015)$ \\
\hline Norway & $0.0018(0.0015)$ \\
\hline South Africa & $0.0016(0.0013)$ \\
\hline Iran & $0.0022(0.0016)$ \\
\hline Turkey & $0.0017(0.0012)$ \\
\hline Israel & $0.0019(0.0013)$ \\
\hline Saudi Arabia & $0.0058(0.0037)$ \\
\hline United Arab Emirates & $0.0038(0.0024)$ \\
\hline China & $0.0222(0.0163)$ \\
\hline Taiwan & $0.0018(0.0017)$ \\
\hline North Korea & $0.0011(0.0008)$ \\
\hline South Korea & $0.0207(0.0161)$ \\
\hline Japan & $0.1832(0.1394)$ \\
\hline India & $0.0037(0.0032)$ \\
\hline Thailand & $0.0017(0.0013)$ \\
\hline Malaysia & $0.0017(0.0013)$ \\
\hline Singapore & $0.0029(0.0020)$ \\
\hline Australia & $0.0064(0.0050)$ \\
\hline WORLD & $0.7375(0.4866)$ \\
\hline \multicolumn{2}{|c|}{ All effects combined } \\
\hline WORLD & $0.9618(0.5093)$ \\
\hline
\end{tabular}


Table 7: Welfare effects for selected countries following reduction of costs of imports to Russia from the United States of America in 2001.

\begin{tabular}{|c|c|}
\hline Country & Welfare effect, \$ (Std.Err.) \\
\hline \multicolumn{2}{|c|}{ Direct effect on importer } \\
\hline Russia & $0.3130(0.0049)$ \\
\hline \multicolumn{2}{|c|}{ Peaceful importer effect } \\
\hline United States of America & $0.3195(0.1929)$ \\
\hline Ukraine & $-0.0024(0.0006)$ \\
\hline \multicolumn{2}{|c|}{ Defense cuts by neighbors } \\
\hline United States of America & $0.3229(0.1599)$ \\
\hline Canada & $0.0135(0.0109)$ \\
\hline Mexico & $0.0090(0.0079)$ \\
\hline Colombia & $0.0022(0.0016)$ \\
\hline Venezuela & $0.0018(0.0014)$ \\
\hline Brazil & $0.0106(0.0080)$ \\
\hline Argentina & $0.0024(0.0020)$ \\
\hline United Kingdom & $0.0318(0.0229)$ \\
\hline Netherlands & $0.0022(0.0019)$ \\
\hline France & $0.0179(0.0136)$ \\
\hline Spain & $0.0068(0.0056)$ \\
\hline Portugal & $0.0016(0.0013)$ \\
\hline Germany & $0.0113(0.0094)$ \\
\hline Italy & $0.0106(0.0084)$ \\
\hline Russia & $0.0068(0.0043)$ \\
\hline Ukraine & $0.0012(0.0004)$ \\
\hline Finland & $0.0021(0.0011)$ \\
\hline Sweden & $0.0028(0.0018)$ \\
\hline Norway & $0.0032(0.0020)$ \\
\hline South Africa & $0.0018(0.0014)$ \\
\hline Iran & $0.0032(0.0021)$ \\
\hline Turkey & $0.0016(0.0011)$ \\
\hline Israel & $0.0021(0.0015)$ \\
\hline Saudi Arabia & $0.0056(0.0033)$ \\
\hline United Arab Emirates & $0.0036(0.0022)$ \\
\hline China & $0.0195(0.0133)$ \\
\hline South Korea & $0.0045(0.0033)$ \\
\hline Japan & $0.0755(0.0452)$ \\
\hline India & $0.0032(0.0025)$ \\
\hline Malaysia & $0.0012(0.0010)$ \\
\hline Singapore & $0.0026(0.0017)$ \\
\hline Philippines & $0.0013(0.0010)$ \\
\hline Australia & $0.0051(0.0040)$ \\
\hline WORLD & $0.6248(0.3617)$ \\
\hline \multicolumn{2}{|c|}{ All effects combined } \\
\hline WORLD & $1.2516(0.5025)$ \\
\hline
\end{tabular}


defense cuts is the product of (i) the marginal effect of such defense cuts on the probability of North Korean aggression against the Unites States, (ii) economic size (proxy for military potential) of North Korea, and (iii) the overall sensitivity of the American welfare to military conflicts.

\section{Conclusion}

The principal message of this paper is that increases in international trade, especially those between belligerent nations, may lead to much larger positive welfare effects than estimated by existing models of trade. In the three counterfactual experiments presented in this paper, the magnitude of the additional welfare effects due to defense spending cuts worldwide is comparable to that of direct welfare effects of increased trade. We also show that the welfare effects of rising trade apply not only to the two trading partners, but also to other nations, often on other continents, due to interdependence of global political relations and of national defense spending.

To assess these effects, we develop a novel structural estimation technique that allows to slice the total welfare effect of rising trade between two nations into several components. First, rising trade makes the importer more dependent on the exporter and lowers the probability of conflict between the two, also makes both better off. Second, more peaceful relations between the two launch a wave of defense spending cuts worldwide, which makes the world even more peaceful. The model allows to show the welfare gains of every country due to defense spending cuts by every other country.

The proposed model has a number of limitations which remain to be addressed in future research. First, the estimation procedure depends on total-peace-level trade volumes, which are not observed if there actually was a conflict in the data. We apply a somewhat simplistic approach to calibrate the peace-level trade; a more advanced method may be developed. Second, we implement a static model and thus do not account for intertemporal effects of conflicts and defense spending, possibly underestimating the true effects.

\section{References}

Acemoglu, D. and P. Yared (2010). Political limits to globalization. Technical report, National Bureau of Economic Research. 
Barbieri, Katherine, O. M. G. K. and B. Pollins (2009). Trading data: Evaluating our assumptions and coding rules. Conflict Management and Peace Science 26(5), 471-479.

Broda, C. and D. E. Weinstein (2006). Globalization and the gains from variety. Quarterly Journal of Economics 121(2), 541-585.

Feenstra, R. C., R. E. Lipsey, H. Deng, A. C. Ma, and H. Mo (2005, January). World trade flows: 1962-2000. Working Paper 11040, National Bureau of Economic Research.

Ghosen, F., G. Palmer, and S. Bennett (2004). The mid 3 data set 1993 2001: Procedures, coding rules, and description. Conflict Management and Peace Science 21, 133-154.

Glick, R. and A. M. Taylor (2010). Collateral damage: Trade disruption and the economic impact of war. The Review of Economics and Statistics 92(1), 102-127.

Hegre, H., J. R. Oneal, and B. Russett (2010). Trade does promote peace: New simultaneous estimates of the reciprocal effects of trade and conflict. Journal of Peace Research 47(6), 763-774.

Martin, P., T. Mayer, and M. Thoenig (2008). Make trade not war? Review of Economic Studies 75(3), 865-900.

Martin, P., T. Mayer, and M. Thoenig (2012). The geography of conflicts and regional trade agreements. American Economic Journal: Macroeconomics 4(4), 1-35.

Mayer, T. and S. Zignago (2011). Notes on cepiis distances measures: The geodist database.

Polachek, S. W. and C. Seiglie (2007). Trade, peace and democracy: an analysis of dyadic dispute. Handbook of Defense Economics 2, 1017-1073.

Singer, J. D., S. Bremer, and J. Stuckey (1972). Capability distribution, uncertainty, and major power war, 1820-1965. in bruce russett (ed). Peace, War, and Numbers, 19-48. Beverly Hills: Sage.

Stinnett, D. M., J. Tir, P. F. Diehl, P. Schafer, and C. Gochman (2002). The correlates of war (cow) project direct contiguity data, version 3.0. Conflict Management and Peace Science 19(2), 59-67.

Stoica, P. and B. C. Ng (1998). On the cramér-rao bound under parametric constraints. Signal Processing Letters, IEEE 5(7), 177-179. 
Vicard, V. (2012). Trade, conflict, and political integration: Explaining the heterogeneity of regional trade agreements. European Economic Review 56(1), 54-71.

Zeev, M. (2005). Dyadic mid dataset (version 2.0). http://psfaculty.ucdavis.edu/zmaoz/dyadmid.html.

\section{A Further details of the estimation procedure}

We calculate the parameter estimates $\hat{\beta}$ by maximizing (18) over $\beta$ subject to (17). The corresponding Lagrangian is

$$
\Lambda(\tilde{\beta}, \mu)=\mathcal{L}(\tilde{\beta})+\mathbf{G}(\tilde{\beta})^{T} \mu \rightarrow \max
$$

where $\mu=\left\{\mu_{i}, \forall i\right\}$ is the vector of Lagrange multipliers, and where superscript $T$ denotes the transposition operator, not to be confused with trade propensities. Assuming an interior solution, the vector of parameter estimates $\hat{\beta}$ and Lagrange multiplier estimates $\mu$ then satisfies

$$
\begin{aligned}
\nabla_{\beta} \mathcal{L}(\hat{\beta})+\nabla_{\beta} \mathbf{G}(\hat{\beta})^{T} \mu & =0, \\
\mathbf{G}(\hat{\beta}) & =0,
\end{aligned}
$$

where $\nabla$ denotes the Jacobian operator, i.e. $\nabla_{x} f(x)$ is the $K_{1} \times K_{2}$ matrix of first partial derivatives of a $1 \times K_{2}$ vector-valued function $f$ of $K_{1} \times 1$ vector of variables $x$.

Our estimation setup seemingly deviates from that of the standard maximum likelihood due to the fact that increased sample size (country-country-year observations) is likely to be accompanied by an increased number of variables (specifically, country-year fixed effects $\sigma_{i}$ ). In fact, however, the number of degrees of freedom does not change: each additional variable is complemented by an additional constraint (17) that uniquely determines the value of that variable. For this reason, the asymptotic properties of our estimates are standard.

The asymptotic variance of the estimates is calculated using a standard technique (e.g., see Wikipedia article on Maximum Likelihood), with some augmentation to account for constraints (17). First, we Taylor-expand the system (20)-(21) around the true value of $\hat{\beta}$, 
i.e. around $\beta$, and around the zero value of $\mu$ :

$$
\begin{aligned}
\nabla_{\beta}(\mathcal{L}(\beta))+\nabla_{\beta \beta^{T}}(\mathcal{L}(\beta))(\hat{\beta}-\beta)+\nabla_{\beta}\left(\mathbf{G}^{T}(\beta)\right) \mu+o(\{\hat{\beta}-\beta ; \mu\}) & =0 \\
\mathbf{G}(\beta)+\nabla_{\beta^{T}} \mathbf{G}(\beta)(\hat{\beta}-\beta)+o(\hat{\beta}-\beta) & =0
\end{aligned}
$$

where $\nabla_{\beta \beta^{T}}$ is the Hessian (matrix of second derivatives) of its argument. The above system may be solved for the unknowns as follows:

$$
\left(\begin{array}{c}
\hat{\beta}-\beta \\
\mu
\end{array}\right)=\left[\begin{array}{cc}
-\nabla_{\beta \beta^{T}}(\mathcal{L}(\beta)) & -\nabla_{\beta^{T}}(\mathbf{G}(\beta)) \\
-\nabla_{\beta}\left(\mathbf{G}^{T}(\beta)\right) & 0
\end{array}\right]^{-1}\left(\begin{array}{c}
\nabla_{\beta}(\mathcal{L}(\beta)) \\
\mathbf{G}(\beta)
\end{array}\right)+o(\{\hat{\beta}-\beta ; \mu\})
$$

The off-diagonal elements of the block matrix in square brackets in (24) are deterministic; we denote the lower-left matrix by $B(\beta) \equiv-\nabla_{\beta}\left(\mathbf{G}^{T}(\beta)\right)$, thus the upper-right matrix is $B^{T}(\beta)$. The upper-left element of the block matrix in square brackets in $(24),-\nabla_{\beta \beta^{T}}(\mathcal{L}(\beta))$, is random (since loglikelihood is a function of empirical conflict statuses, which are in turn functions of income and trade shocks), and converges in probability to a square positivedefinite matrix $n H(\beta)$, where $H(\beta) \equiv-\mathrm{E}_{\epsilon, \lambda} \nabla_{\beta \beta^{T}}(\mathcal{L}(\beta))$, and where $n$ is the number of country-country-year observations that enter the loglikelihood.

In the block vector in brackets on the right-hand side of (24), the lower element, $\mathbf{G}(\beta)$, is deterministic and is equal to zero, while the upper element, $\nabla_{\beta}(\mathcal{L}(\beta))$, is random and has an expectation of zero. Thus, our estimates $\hat{\beta}$ and $\mu$ have expectations of $\beta$ and zero, respectively. To find the asymptotic variance of $\hat{\beta}$, we apply the Central Limit Theorem to obtain

$$
\begin{aligned}
\sqrt{n}(\hat{\beta}-\beta) & =n J(\beta) \frac{1}{\sqrt{n}} \nabla_{\beta}(\mathcal{L}(\beta))+o(\{\hat{\beta}-\beta ; \mu\}) \\
& \rightarrow^{d} \quad N\left(0, \mathrm{E}_{\epsilon, \lambda} n J(\beta) \mathrm{E}_{\epsilon, \lambda}\left(\nabla_{\beta}(\mathcal{L}(\beta))\right)^{2} \mathrm{E}_{\epsilon, \lambda} n J(\beta)\right)
\end{aligned}
$$

where $J(\beta)$ is the upper-left block of the inverse block matrix shown in (24).

One can show that (dropping some function arguments)

$$
\mathrm{E}_{\epsilon, \lambda} J(\beta)=\frac{1}{n} H^{-1}-\frac{1}{n} H^{-1} B^{T}\left(B H^{-1} B^{T}\right)^{-1} B H^{-1},
$$

thus $n \mathrm{E}_{\epsilon, \lambda} J(\beta)$ does not depend on $n$. We can also show that $\mathrm{E}_{\epsilon, \lambda}\left(\nabla_{\beta}(\mathcal{L}(\beta))\right)^{2}=H$. Thus, 
the asymptotic variance of $\hat{\beta}$ is equal to (cf.(25))

$$
\begin{aligned}
\mathrm{E}_{\epsilon, \lambda}(\hat{\beta}-\beta)^{2} & =\frac{1}{n}\left(H^{-1}-H^{-1} B^{T}\left(B H^{-1} B^{T}\right)^{-1} B H^{-1}\right) H\left(H^{-1}-H^{-1} B^{T}\left(B H^{-1} B^{T}\right)^{-1} B H^{-1}\right) \\
& =\frac{1}{n} H^{-1}-\frac{1}{n} H^{-1} B^{T}\left(B H^{-1} B^{T}\right)^{-1} B H^{-1}
\end{aligned}
$$

Stoica and $\mathrm{Ng}$ (1998) prove that (26) is equal to the Cramer-Rao variance lower bound, hence the proposed estimator of unknown model parameters is asymptotically efficient.

In the numerical procedure, we can approximate $n H(\beta)$ by $-\nabla_{\beta \beta^{T}}(\mathcal{L}(\hat{\beta}))$, and $B(\beta)$ by $B(\hat{\beta})$.

\section{B Data details}

\section{B.1 List of countries dropped from sample}

A country was dropped from the sample if (i) it had no defense spending data in any year, or (ii) it had data on imports from less than 5 trading partners in 2001; we also drop Nauru, the second-smallest nation in the world, for which we could not construct the GDP data for some years. The list of dropped countries is as follows: St. Kitts and Nevis, Monaco, Liechtenstein, Andorra, San Marino, Comoros, Tonga, Nauru, Marshall Islands, Federated States of Micronesia. Each of these had a GDP of under 3 billion dollars and no recorded history of defense spending.

\section{B.2 Country statistics}

\begin{tabular}{|c|c|c|c|}
\hline Country & $\begin{array}{l}\text { Defense spending, } \\
\% \text { of GDP }\end{array}$ & $\begin{array}{l}\text { Conflict length } \\
\text { aggregated across } \\
\text { neighbors, country- } \\
\text { years }\end{array}$ & $\begin{array}{l}\text { Total imports, } \% \text { of } \\
\text { GDP }\end{array}$ \\
\hline United States of America & 3.00 & 1.5081 & 11.7180 \\
\hline Canada & 1.10 & 0.1048 & 32.8808 \\
\hline Bahamas & 0.44 & 0 & 49.1025 \\
\hline Cuba & 2.31 & 0 & 10.6750 \\
\hline Haiti & 0 & 0 & 18.0337 \\
\hline
\end{tabular}

Table 8: Some country statistics, year 2001 


\begin{tabular}{|c|c|c|c|}
\hline Country & $\begin{array}{l}\text { Defense spending, } \\
\% \text { of GDP }\end{array}$ & $\begin{array}{l}\text { Conflict length } \\
\text { aggregated across } \\
\text { neighbors, country- } \\
\text { years }\end{array}$ & $\begin{array}{l}\text { Total imports, } \% \text { of } \\
\text { GDP }\end{array}$ \\
\hline Dominican Republic & 0.62 & 0 & 38.1901 \\
\hline Jamaica & 0.50 & 0 & 36.1070 \\
\hline Trinidad and Tobago & 0.75 & 0 & 40.3019 \\
\hline Barbados & 0.50 & 0 & 40.8193 \\
\hline Dominica & 1.00 & 0 & 38.3043 \\
\hline Grenada & 0 & 0 & 34.0402 \\
\hline St. Lucia & 0 & 0 & 77.3815 \\
\hline St. Vincent and the Grenadines & 0 & 0 & 39.6814 \\
\hline Antigua and Barbuda & 0.50 & 0 & 65.6241 \\
\hline Mexico & 0.60 & 0 & 29.2754 \\
\hline Belize & 0.90 & 0.3656 & 50.6530 \\
\hline Guatemala & 0.80 & 0.3656 & 29.2522 \\
\hline Honduras & 0.70 & 0.2043 & 37.6782 \\
\hline El Salvador & 1.30 & 0 & 35.1261 \\
\hline Nicaragua & 0.80 & 0.3065 & 39.1568 \\
\hline Costa Rica & 0 & 0 & 26.5591 \\
\hline Panama & 0 & 0 & 22.0094 \\
\hline Colombia & 3.00 & 0.1022 & 12.6043 \\
\hline Venezuela & 1.50 & 0 & 13.1988 \\
\hline Guyana & 1.50 & 0 & 82.3861 \\
\hline Suriname & 3.14 & 0 & 84.0103 \\
\hline Ecuador & 1.60 & 0 & 26.7463 \\
\hline Peru & 1.80 & 0 & 14.4915 \\
\hline Brazil & 1.80 & 0 & 10.9602 \\
\hline Bolivia & 2.10 & 0 & 20.8488 \\
\hline Paraguay & 1.10 & 0 & 34.1903 \\
\hline Chile & 3.80 & 0 & 23.1375 \\
\hline Argentina & 1.10 & 0 & 7.3384 \\
\hline Uruguay & 2.80 & 0 & 14.7288 \\
\hline United Kingdom & 2.40 & 0.9220 & 20.7991 \\
\hline Ireland & 0.70 & 0 & 43.1469 \\
\hline Netherlands & 1.50 & 0.0591 & 50.4285 \\
\hline Belgium & 1.40 & 0 & 77.5283 \\
\hline Luxembourg & 0.60 & 0 & 57.2586 \\
\hline France & 2.50 & 0.1667 & 24.8987 \\
\hline Switzerland & 1.10 & 0 & 32.2164 \\
\hline
\end{tabular}




\begin{tabular}{|c|c|c|c|}
\hline Country & $\begin{array}{l}\text { Defense spending, } \\
\% \text { of GDP }\end{array}$ & $\begin{array}{l}\text { Conflict length } \\
\text { aggregated across } \\
\text { neighbors, country- } \\
\text { years }\end{array}$ & $\begin{array}{l}\text { Total imports, } \% \text { of } \\
\text { GDP }\end{array}$ \\
\hline Spain & 1.20 & 0.0591 & 23.3166 \\
\hline Portugal & 1.90 & 0.0591 & 31.5640 \\
\hline Germany & 1.50 & 0.0591 & 25.5818 \\
\hline Poland & 1.80 & 0 & 26.2372 \\
\hline Austria & 1.00 & 0 & 39.2347 \\
\hline Hungary & 1.70 & 0 & 62.6157 \\
\hline Czech Republic & 2.00 & 0 & 63.6119 \\
\hline Slovakia & 1.70 & 0 & 53.3359 \\
\hline Italy & 2.00 & 0 & 21.1190 \\
\hline Malta & 0.70 & 0 & 121.5685 \\
\hline Albania & 1.20 & 0.1022 & 32.2704 \\
\hline Macedonia & 1.90 & 0 & 44.8176 \\
\hline Croatia & 3.10 & 0 & 38.1870 \\
\hline Yugoslavia & 5.50 & 0.1022 & 35.8826 \\
\hline Bosnia and Herzegovina & 2.45 & 0 & 49.8555 \\
\hline Slovenia & 1.10 & 0 & 50.4138 \\
\hline Greece & 3.60 & 0.3871 & 21.6080 \\
\hline Cyprus & 3.00 & 0.5511 & 40.8713 \\
\hline Bulgaria & 2.70 & 0 & 51.2197 \\
\hline Moldova & 0.40 & 0 & 59.2851 \\
\hline Romania & 2.50 & 0 & 37.6833 \\
\hline Russia & 3.70 & 0.7823 & 11.8982 \\
\hline Estonia & 1.40 & 0 & 83.9315 \\
\hline Latvia & 0.90 & 0 & 41.9360 \\
\hline Lithuania & 1.70 & 0.0860 & 51.8912 \\
\hline Ukraine & 3.60 & 0 & 41.3333 \\
\hline Belarus & 1.30 & 0.0860 & 67.6823 \\
\hline Armenia & 3.60 & 0 & 41.0939 \\
\hline Georgia & 0.60 & 0.2016 & 23.4704 \\
\hline Azerbaijan & 2.30 & 0.4382 & 25.0072 \\
\hline Finland & 1.30 & 0 & 22.6418 \\
\hline Sweden & 2.00 & 0 & 27.5693 \\
\hline Norway & 1.70 & 0.0134 & 18.5413 \\
\hline Denmark & 1.50 & 0 & 27.3757 \\
\hline Iceland & 0 & 0 & 29.6218 \\
\hline Cape Verde & 1.30 & 0 & 42.9252 \\
\hline
\end{tabular}




\begin{tabular}{|c|c|c|c|}
\hline Country & $\begin{array}{l}\text { Defense spending, } \\
\% \text { of GDP }\end{array}$ & $\begin{array}{l}\text { Conflict length } \\
\text { aggregated across } \\
\text { neighbors, country- } \\
\text { years }\end{array}$ & $\begin{array}{l}\text { Total imports, } \% \text { of } \\
\text { GDP }\end{array}$ \\
\hline Sao Tome and Principe & no data & 0 & 70.5393 \\
\hline Guinea-Bissau & 4.40 & 0 & 46.9711 \\
\hline Equatorial Guinea & 0.23 & 0 & 19.3426 \\
\hline Gambia & 1.00 & 0 & 94.9333 \\
\hline Mali & 2.20 & 0 & 35.3301 \\
\hline Senegal & 1.30 & 0 & 35.2381 \\
\hline Benin & 0.60 & 0 & 25.9257 \\
\hline Mauritania & 3.50 & 0 & 49.8529 \\
\hline Niger & 1.20 & 0 & 17.0250 \\
\hline Cote DIvoire & 0.75 & 0 & 23.0957 \\
\hline Guinea & 1.50 & 0.7554 & 18.0433 \\
\hline Burkina Faso & 1.20 & 0 & 16.9399 \\
\hline Liberia & 4.41 & 0.4785 & 815.1370 \\
\hline Sierra Leone & 3.70 & 0.4382 & 50.4026 \\
\hline Ghana & 0.70 & 0 & 49.9575 \\
\hline Togo & 2.33 & 0 & 26.5074 \\
\hline Cameroon & 1.30 & 0.0134 & 18.9304 \\
\hline Nigeria & 0.80 & 0 & 16.5178 \\
\hline Gabon & 1.80 & 0 & 30.2574 \\
\hline Central African Republic & 1.55 & 0.0134 & 10.5887 \\
\hline Chad & 1.90 & 0 & 21.5112 \\
\hline Congo & 2.86 & 0 & 21.2783 \\
\hline Democratic Republic of Congo & 8.35 & 0.8441 & 14.4494 \\
\hline Uganda & 2.50 & 2.2823 & 17.3810 \\
\hline Kenya & 1.30 & 0 & 27.2178 \\
\hline Tanzania & 1.50 & 0 & 17.4247 \\
\hline Burundi & 6.00 & 0 & 19.5625 \\
\hline Rwanda & 3.50 & 2.2823 & 11.7796 \\
\hline Somalia & 2.56 & 0 & 19.8681 \\
\hline Djibouti & 5.10 & 0 & 121.4357 \\
\hline Ethiopia & 7.50 & 0 & 19.4002 \\
\hline Eritrea & 32.70 & 0 & 27.2792 \\
\hline Angola & 6.40 & 1.8253 & 38.5701 \\
\hline Mozambique & 1.30 & 0 & 21.9129 \\
\hline Zambia & 0.74 & 0.9812 & 29.9271 \\
\hline Zimbabwe & 4.70 & 0.8441 & 22.2083 \\
\hline
\end{tabular}




\begin{tabular}{|c|c|c|c|}
\hline Country & $\begin{array}{l}\text { Defense spending, } \\
\% \text { of GDP }\end{array}$ & $\begin{array}{l}\text { Conflict length } \\
\text { aggregated across } \\
\text { neighbors, country- } \\
\text { years }\end{array}$ & $\begin{array}{l}\text { Total imports, } \% \text { of } \\
\text { GDP }\end{array}$ \\
\hline Malawi & 0.70 & 0 & 25.1134 \\
\hline South Africa & 1.50 & 0 & 22.9668 \\
\hline Namibia & 2.70 & 0.8441 & 14.9584 \\
\hline Lesotho & 4.00 & 0 & 14.1348 \\
\hline Botswana & 3.30 & 0 & 4.8122 \\
\hline Swaziland & 1.50 & 0 & 6.3726 \\
\hline Madagascar & 1.20 & 0 & 14.7020 \\
\hline Mauritius & 0.20 & 0 & 44.2940 \\
\hline Seychelles & 1.70 & 0 & 79.3677 \\
\hline Morocco & 2.30 & 0 & 29.2162 \\
\hline Algeria & 3.40 & 0 & 17.8380 \\
\hline Tunisia & 1.80 & 0 & 42.6296 \\
\hline Libya & 3.10 & 0 & 15.7767 \\
\hline Sudan & 4.50 & 0 & 14.3243 \\
\hline Iran & 3.70 & 0.4409 & 14.6389 \\
\hline Turkey & 3.70 & 1.0699 & 20.1403 \\
\hline Iraq & 7.24 & 2.5054 & 29.5683 \\
\hline Egypt & 3.20 & 0 & 11.9293 \\
\hline Syria & 5.50 & 0.5000 & 25.2845 \\
\hline Lebanon & 5.40 & 0.9973 & 34.8417 \\
\hline Jordan & 6.30 & 0 & 51.6011 \\
\hline Israel & 8.00 & 1.4973 & 25.0551 \\
\hline Saudi Arabia & 10.60 & 0.6452 & 20.3195 \\
\hline Yemen & 4.40 & 0 & 23.9812 \\
\hline Kuwait & 7.20 & 0.2473 & 22.0456 \\
\hline Bahrain & 4.00 & 0 & 46.4132 \\
\hline Qatar & 7.08 & 0 & 20.4877 \\
\hline United Arab Emirates & 9.40 & 0 & 30.5749 \\
\hline Oman & 10.80 & 0 & 28.9443 \\
\hline Afghanistan & 9.95 & 1.5995 & 22.6432 \\
\hline Turkmenistan & 6.28 & 0 & 62.9105 \\
\hline Tajikistan & 1.20 & 0.0081 & 63.5987 \\
\hline Kyrgyzstan & 2.90 & 0 & 30.9817 \\
\hline Uzbekistan & 1.20 & 0.0672 & 20.8336 \\
\hline Kazakhstan & 0.80 & 0 & 29.2810 \\
\hline China & 1.90 & 1.0753 & 23.3518 \\
\hline
\end{tabular}




\begin{tabular}{|c|c|c|c|}
\hline Country & $\begin{array}{l}\text { Defense spending, } \\
\% \text { of GDP }\end{array}$ & $\begin{array}{l}\text { Conflict length } \\
\text { aggregated across } \\
\text { neighbors, country- } \\
\text { years }\end{array}$ & $\begin{array}{l}\text { Total imports, } \% \text { of } \\
\text { GDP }\end{array}$ \\
\hline Mongolia & 2.10 & 0 & 49.2217 \\
\hline Taiwan & 2.40 & 0.4274 & 34.1775 \\
\hline North Korea & 9.85 & 0.4839 & 15.6948 \\
\hline South Korea & 2.60 & 0.4839 & 27.3303 \\
\hline Japan & 1.00 & 0.1586 & 8.4593 \\
\hline India & 3.10 & 0.4677 & 9.5603 \\
\hline Bhutan & 4.16 & 0 & 5.7107 \\
\hline Pakistan & 3.70 & 0.4704 & 14.1162 \\
\hline Bangladesh & 1.30 & 0.0027 & 16.5070 \\
\hline Myanmar & 2.30 & 0.2177 & 40.6860 \\
\hline Sri Lanka & 5.00 & 0 & 33.7569 \\
\hline Maldives & 4.56 & 0 & 49.8122 \\
\hline Nepal & 0.80 & 0 & 14.6684 \\
\hline Thailand & 1.50 & 0.2177 & 49.8994 \\
\hline Cambodia & 2.20 & 0 & 34.6157 \\
\hline Laos & 0.80 & 0 & 39.3159 \\
\hline Vietnam & 7.19 & 0 & 47.8934 \\
\hline Malaysia & 1.60 & 0 & 77.3222 \\
\hline Singapore & 4.60 & 0 & 126.1993 \\
\hline Brunei & 5.70 & 0 & 23.4061 \\
\hline Philippines & 1.60 & 0.0806 & 43.5333 \\
\hline Indonesia & 0.53 & 0 & 19.4895 \\
\hline Australia & 1.80 & 0.1048 & 17.4795 \\
\hline Papua New Guinea & 0.90 & 0 & 35.6907 \\
\hline New Zealand & 1.20 & 0 & 24.9090 \\
\hline Vanuatu & 0 & 0 & 63.8031 \\
\hline Solomon Islands & 0 & 0 & 24.2162 \\
\hline Kiribati & 0 & 0 & 69.0734 \\
\hline Tuvalu & 0 & 0 & 87.8851 \\
\hline Fiji & 1.90 & 0 & 43.7271 \\
\hline Palau & 0 & 0 & 21.0989 \\
\hline Samoa & 0 & 0 & 109.0048 \\
\hline
\end{tabular}

